\title{
A review of the fate of micropollutants in wastewater treatment plants
}

\author{
Jonas Margot, ${ }^{*}$ Luca Rossi, David A. Barry and Christof Holliger
}

\begin{abstract}
Municipal wastewaters are contaminated by a wide range of chemicals, from surfactants to heavy metals, including pharmaceutical residues, personal care products, various household chemicals, and biocides/pesticides. Their release into the environment, where they may generate adverse effects on aquatic organisms, depends on their fate in wastewater treatment plants (WWTPs). The sources, the typical concentrations and the fate of more than 160 micropollutants of various classes in conventional WWTPs, were investigated in order to estimate surface water contamination, risks for aquatic organisms, and to propose means to reduce their release into the environment. Relatively hydrophobic pollutants such as heavy metals, persistent organic pollutants (POPs), brominated flame retardants, and several personal care products (PCPs), as well as easily biodegradable pollutants such as surfactants, plastic additives, hormones, several PCPs, some pharmaceuticals, and household chemicals, are usually well removed (>70\%) in WWTPs, either by sorption onto sewage sludge or by biodegradation. Good removal efficiencies, however, do not mean that the effluent concentrations will not potentially affect aquatic life, as some of these compounds are toxic at very low concentrations. More hydrophilic and poorly-to-moderately biodegradable pollutants such as several pharmaceuticals, pesticides, and household chemicals (corrosion inhibitors, sweeteners, chelating agents, phosphorus flame retardants) are only poorly removed during treatments. To decrease their discharge into surface waters, source control combined to advanced treatments such as ozonation and adsorption onto activated carbon are necessary. ๑ 2015 Wiley Periodicals, Inc.
\end{abstract}

How to cite this article:

WIREs Water 2015. doi: 10.1002/wat2.1090

\section{INTRODUCTION}

$\mathrm{T}$ he increasing worldwide consumption of chemical products has led to increasing chemical pollution of surface and groundwaters, with still largely unknown effects on human health and aquatic life. Contamination of natural water by thousands of chemical compounds despite, for most of them, very low concentrations $\left(\mathrm{pg}-\mu \mathrm{g} \mathrm{L}^{-1}\right)$, raises considerable ecological issues and is a major public concern almost

*Correspondence to: Jonas.margot@epfl.ch

School of Architecture, Civil and Environmental Engineering (ENAC), Ecole Polytechnique Fédérale de Lausanne (EPFL), Lausanne, Switzerland

Conflict of interest: The authors have declared no conflicts of interest for this article. all around the world. ${ }^{1}$ Many of these so called 'micropollutants' have an urban origin and are used daily in homes, workplaces, or in the urban environment. Most end up in sewers. This is obviously the case for 'down the drain' products, such as detergents and their additives, or personal care products, but also for pharmaceuticals and their metabolites that are excreted in urine and feces, and several household chemicals such as food or plastic additives, or flame retardants contained in textiles. Municipal wastewater is also contaminated by nondomestic pollutants such as heavy metals, pesticides, or hydrocarbons, leached during rain runoff from roads, buildings, and urban parks and gardens.

If these compounds are not removed in wastewater treatment plants (WWTPs), they may impact 
wildlife in receiving waters. For instance, feminization of fish and mussels as well as intersex and reproductive disruption in fish were observed in several rivers downstream of WWTP outfalls, probably related to the release of estrogenic endocrine disrupters. ${ }^{2-9}$ Several other adverse effects were observed downstream of WWTP outfalls, especially in case of low dilution of effluents, such as neuroendrocinal alterations and oxidative stress in freshwater mussels, ${ }^{10,11}$ histopathological effects in fish, ${ }^{7,12}$ alteration of macroinvertebrate communities and gammarid health (fecundity, sex ratio, stress), ${ }^{13,14}$ or reduction in leaf litter breakdown by gammarid crustaceans, which may impact the whole aquatic food web downstream of WWTPs. ${ }^{15}$

Understanding the fate of these pollutants in conventional WWTPs is therefore necessary to evaluate surface water contamination and to develop measures to reduce their release into the environment. This review explains the main removal mechanisms and the fate of certain classes of micropollutants in conventional treatment systems, as well as proposes means to improve micropollutant removal from wastewater.

\section{REMOVAL MECHANISMS IN CONVENTIONAL WWTPS}

Currently, conventional WWTPs are designed to remove the solid wastes, suspended solids, easily biodegradable dissolved organic matter and nutrients (phosphorus and nitrogen) from wastewater (Figure 1). Despite the fact that they were not designed to treat other kind of pollutants, many micropollutants are affected by the physical, chemical, and biological processes occurring during treatment.

The main mechanisms for micropollutant removal in conventional wastewater treatment are
(Figure 2): (1) sorption onto particulate matter (sludge), (2) biological transformation, (3) volatilization, and (4) abiotic degradation. Sorption and volatilization consist of a transfer of the micropollutant from one compartment (water) to another (solid or gas) whereas degradation leads to the transformation of the micropollutant. Complete mineralization produces water, $\mathrm{CO}_{2}$, and minerals.

\section{Sorption}

Sorption onto sludge or particulate matter can be an important removal mechanism for hydrophobic or positively charged micropollutants, especially if they are poorly biodegradable. Adsorption onto biological sludge can be differentiated into two main processes ${ }^{80}$ : (1) hydrophobic interactions between hydrophobic pollutants and suspended solids, extracellular polymeric substances (EPS) or the lipophilic cell membrane of microorganisms and (2) electrostatic interactions between positively charged groups of the pollutant and the mainly negatively charged surfaces of microorganisms and effluent organic matter (EfOM).

Micropollutants not only sorb to particulate matter, but also onto colloidal particles $(1 \mathrm{~nm}$ to 1 $\mu \mathrm{m})$, which are considered as part of the 'dissolved' phase. ${ }^{81}$ Sorption onto dissolved or colloidal matter (DCM) increases the solubility of hydrophobic substances, limiting their removal by adsorption onto the sludge. ${ }^{82-84} \mathrm{~A}$ diagram of the adsorption process in wastewater is presented in Figure 3.

Adsorption is a transfer of pollutant from the liquid to the solid phase. Therefore, the fate of sorbed pollutants will depend on the fate of the solids (incineration, disposal in landfills, or reuse in agriculture). Information concerning concentrations found in sewage sludge was presented by Margot. ${ }^{79}$

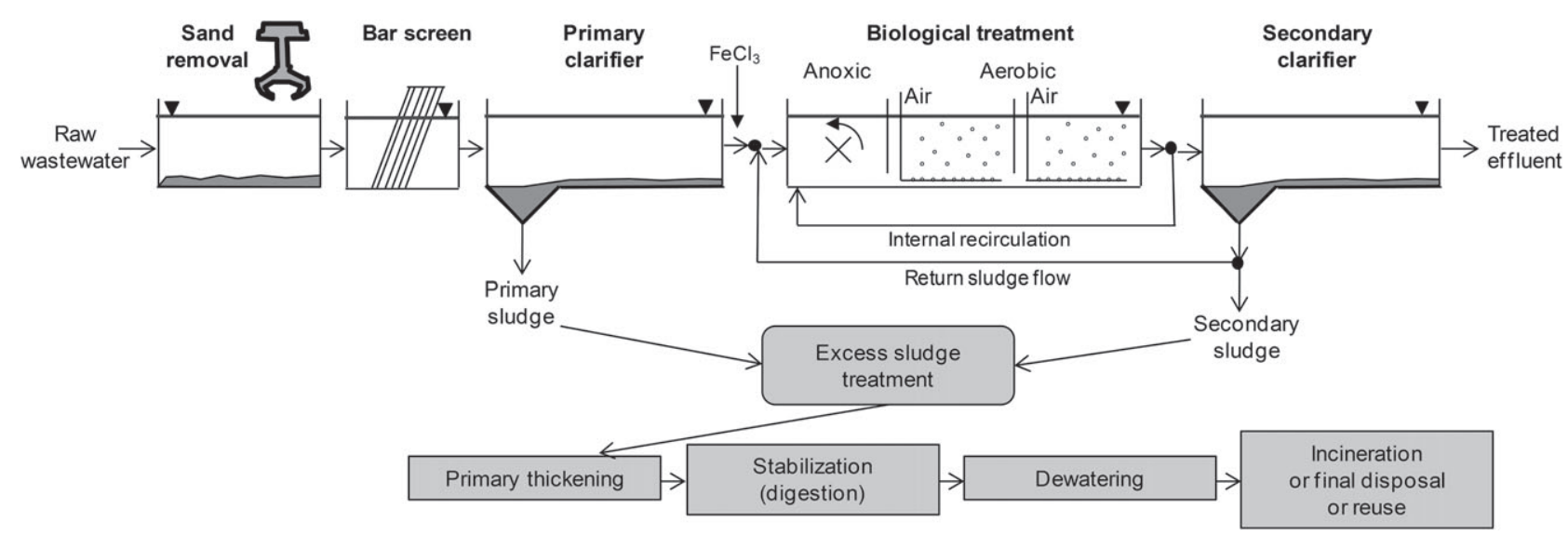

FIG URE 1 | Scheme of a conventional WWTP with activated sludge for the removal of biodegradable organic matter, nitrification, denitrification, and chemical phosphorus removal (precipitation with $\mathrm{FeCl}_{3}$ ). The sludge produced is then treated to be either reused as fertilizer or incinerated. 


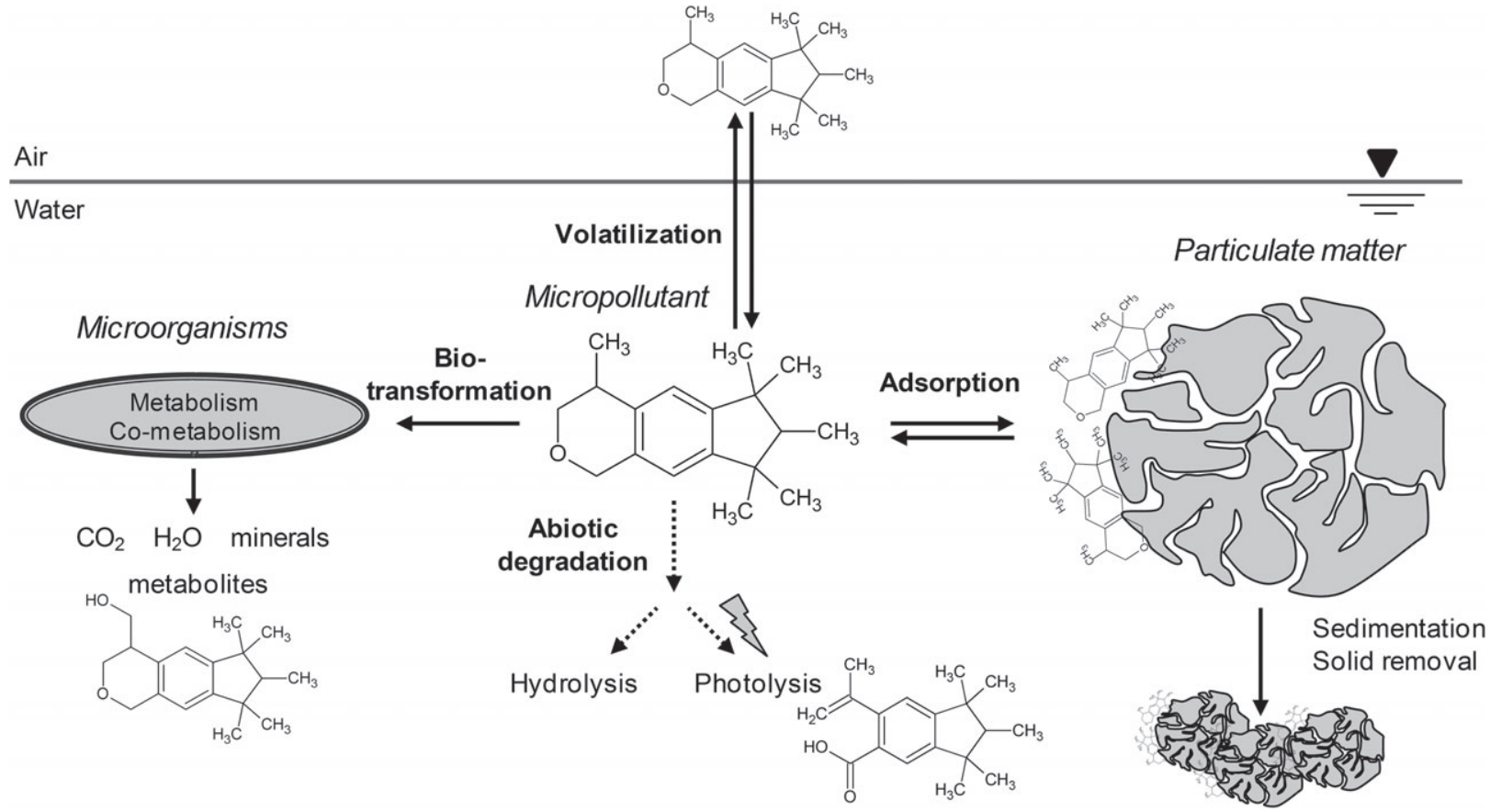

FIG URE 2 | Main removal mechanisms of micropollutants in conventional WWTPs (example of the polycyclic musk galaxolide). This compound is mainly eliminated by sorption on particulate matter and removed with the excess sludge. Biological degradation and volatilization processes may play also a role (10-15\%) in the elimination of this compound (see Table 1).

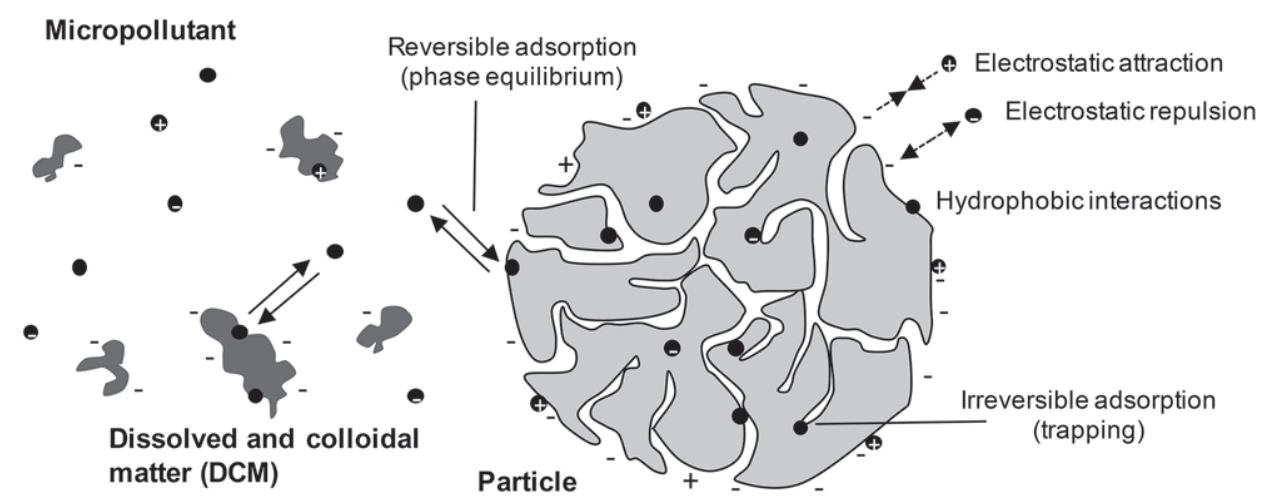

FIGURE 3 | Micropollutant adsorption onto sludge and onto dissolved and colloidal matter.

\section{Biological Transformation}

For many hydrophilic organic micropollutants, biological transformation is the main removal mechanism during wastewater treatment. Micropollutant concentrations in wastewater are usually too low $\left(\mathrm{ng} \mathrm{L}^{-1}\right.$ to $\mu \mathrm{g} \mathrm{L}^{-1}$ ) to support the growth of microorganisms or to induce the corresponding enzymes and/or cofactors for their biodegradation. Therefore, biological transformation of micropollutants generally requires the presence of other growth substrates (carbon and energy sources). ${ }^{85}$ Biotransformation of trace contaminants can be separated in two main processes: (1) metabolic reactions on mixed substrate or (2) co-metabolic reactions (Figure 4).
During metabolic reactions on mixed substrates, microorganisms use organic micropollutants as a growth substrate, together with other organic compounds. These substrates are used as energy (catabolism) and/or carbon source (anabolism) for their cell development (maintenance, growth and reproduction). ${ }^{86}$

During co-metabolic reactions, micropollutants are not used as a growth substrate but are biologically transformed by side reactions catalyzed by unspecific enzymes (such as mono- or di-oxygenases, $\mathrm{N}$-acetyltransferases, hydrolases) or cofactors produced during the microbial conversion of the growth substrate. ${ }^{87}$ 
(a) Metabolic reactions on mixed growth substrate

\section{By-products}

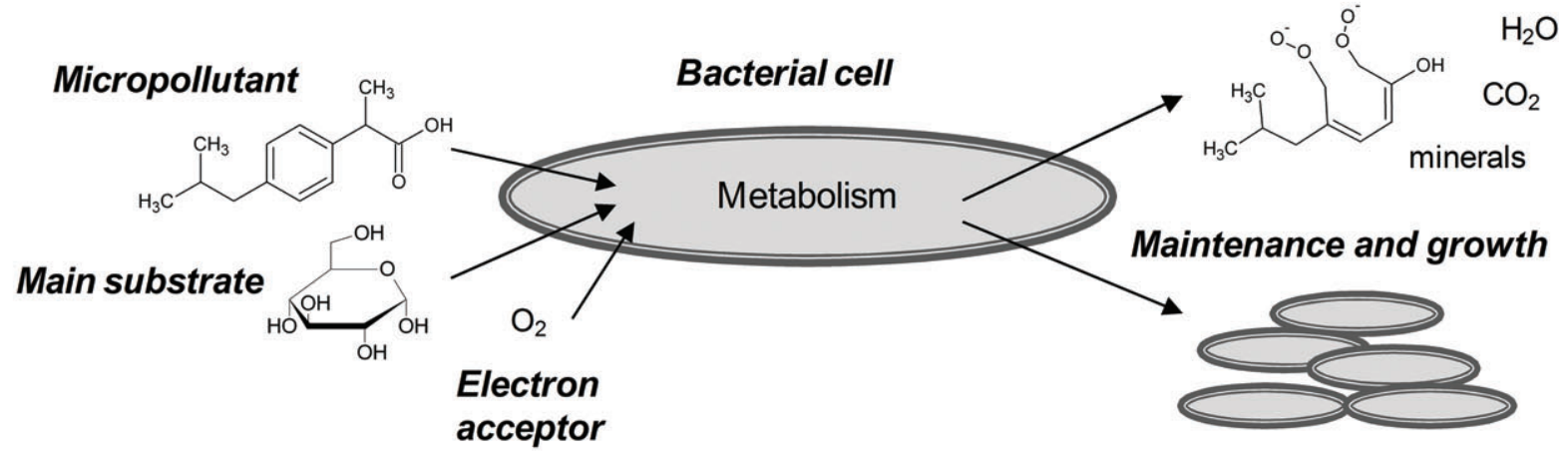

(b) Co-metabolic reactions

Micropollutant

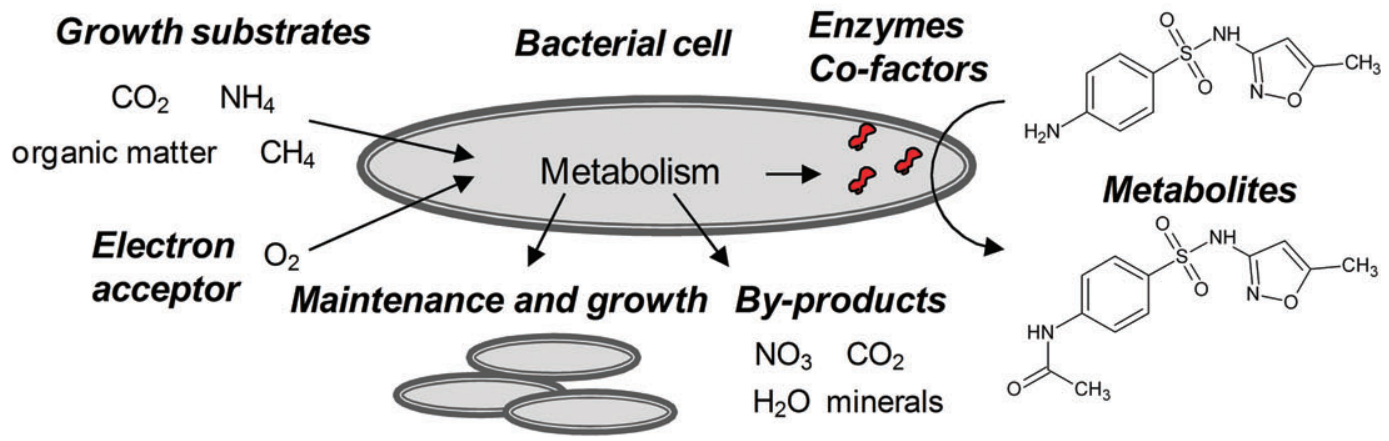

FIG URE 4 | Micropollutant biotransformation by (a) metabolic (e.g., ibuprofen) or (b) co-metabolic processes (e.g., sulfamethoxazole).

The fraction of pollutant removed by biodegradation (by metabolism or co-metabolism) in the secondary treatment depends mainly on the amount of microorganisms present (i.e., indirectly the sludge concentration), the type of microorganisms (sludge composition), the biodegradability of the pollutant by these microorganisms, and the hydraulic retention time within the reactor (as degradation usually follows pseudo-first order kinetics) ${ }^{88}$ The biodegradation rate can also be influenced by temperature (e.g., higher degradation rate at $20^{\circ} \mathrm{C}$ compared with $10^{\circ} \mathrm{C}$ ), $\mathrm{pH}$ (influences the enzymatic activity and cell uptake, with usually higher uptake of the neutral (noncharged) species), redox conditions (usually higher under aerobic conditions), and the availability of a co-substrate. ${ }^{80,89}$

\section{Volatilization}

Volatilization of micropollutants can occur during wastewater treatment, occurring as surface volatilization but more significantly by stripping during aeration. The transfer of the pollutant from water to air depends essentially on the volatility of the compound (Henry's law constant $K_{H}$ ) and the operating condition of the process (aeration, agitation, temperature, and atmospheric pressure). ${ }^{81}$ Stripping should not be considered as an option for water treatment if the gas flow is not treated afterwards, otherwise the WWTP could cause atmospheric pollution.

\section{Abiotic Degradation}

Organic micropollutants can potentially be degraded during wastewater treatment by abiotic reactions, such as photolysis or hydrolysis. Photolysis, which occurs when a photon is absorbed by a compound leading to chemical bond cleavage, is very restricted in conventional WWTPs due to the low surface-to-volume ratio available for sunlight irradiation and the high turbidity of the wastewater, which strongly limits the penetration of light into the water. Hydrolysis, which is the result of the cleavage of chemical bonds by substitution of an atom or group of atoms in an organic compound by a water molecule (or hydroxide ion), can be considered as a negligible removal mechanism in WWTPs, except for a few compounds such as some $\beta$-lactam, macrolide, and tetracycline antibiotics. ${ }^{90,91}$ Therefore, abiotic degradation is not expected to be a significant removal mechanism in WWTPs. 


\section{FATE OF SELECTED CLASSES OF MICROPOLLUTANTS IN CONVENTIONAL WWTPS}

As presented above, the fate of micropollutants during wastewater treatment depends mainly on their physicochemical characteristics (hydrophobicity, biodegradability, volatility) and the type of treatment. The fate of the main classes of micropollutants found in municipal wastewater during conventional wastewater treatments (equivalent to activated sludge with partial nitrification) is described below and synthesized in Table 1 . This table also summarizes other key information on the different classes of micropollutants in order to estimate their risk for the environment [chronic environmental quality standards for inland water (EQS) and predicted no-effect concentrations (PNEC)]. EQSs and PNECs are limits of concentrations in surface waters below which no adverse effect of the substance on sensitive aquatic organisms is expected.

\section{Surfactants}

Surfactants are widely used in household applications for detergents and cleaners but also for industrial and institutional cleaning, personal care, textiles, paint additives, lacquers, and plastics. ${ }^{16}$ The most consumed surfactants in 2005 were soaps $(23.5 \%)$, linear alkylbenzene sulfonates (LAS, $16.6 \%$ ), alcohol ethoxylates (AE, 17.9\%), and alcohol ether sulfates (AES, 13.5\%). The remaining surfactants used were mostly secondary alkane sulfonates (SAS, 2.2\%), alcohol sulfates (AS, 2\%), alkyl phenol ethoxylate (APEO, $1 \%)$, cationic $(6.8 \%)$, and amphoteric $(2.5 \%)$ surfactants. ${ }^{16}$ Once used, most of these chemicals are directly discharged into sewers ('down the drain' pathway). Therefore, because of their high consumption (>7.5 $\mathrm{g} \mathrm{day}^{-1}$ capita $^{-1}$ ), concentrations of surfactants in raw wastewater are relatively high $(>40 \mathrm{mg}$ $\left.\mathrm{L}^{-1}\right),{ }^{18}$ which may represent $20-30 \%$ of the dissolved organic carbon (DOC) of the wastewater (assumption of $100 \mathrm{mg}$ DOC $\mathrm{L}^{-1}$ ). Fortunately, most household surfactants are easily biodegradable and well removed $(>95 \%)$ in WWTPs (cf. Table 1). Because of their low volatility (high surface-active properties and polarity), they are mainly removed by biodegradation (70 to more than $95 \%$ ) and adsorption (up to $30 \%) .{ }^{92}$ Because of their high influent concentration, surfactants are still found at relatively high concentrations $\left(1-150 \mu \mathrm{g} \mathrm{L}^{-1}\right)$ in WWTP effluents, which is often higher than their reported PNEC (Table 1). Thus, despite their degradability, the constant release (pseudo-persistence) of such compounds means that effects on sensitive aquatic organisms in the proximity of the discharge point cannot be excluded in the case of low effluent dilution.

\section{Pharmaceuticals}

About 3000 pharmaceutical compounds are commercially available in Europe. ${ }^{93}$ Over $300 \mathrm{mg}$ of active ingredients are, on average, consumed every day per inhabitant in Western Europe, of which $99 \%$ of the mass is dominated by around 60 compounds. ${ }^{94,95}$ Once ingested, these pharmaceuticals find their way into urine and feces, partially as the original molecule (the part not metabolized in the body) and partially as metabolites, which are mainly hydroxylated, hydrolyzed, or conjugated forms of the parent compound. ${ }^{96}$ The estimated total load of pharmaceuticals (parent compounds) into sewers is around $70 \mathrm{mg}$ day $^{-1}$ capita $^{-1}$, which corresponds to about 200-250 $\mu \mathrm{g} \mathrm{L} \mathrm{L}^{-1} \cdot 42,95$ Depending on the quantity of drugs consumed and their excretion rates $(0$ to $100 \%$ ), concentrations of individual pharmaceuticals in raw wastewater can vary from less than $1 \mathrm{ng} \mathrm{L}^{-1}$ to over $100 \mu \mathrm{g} \mathrm{L}^{-1}$. The most abundant pharmaceuticals in wastewater (found at 0.1 to more than $10 \mu \mathrm{g} \mathrm{L}^{-1}$ ) are, not surprisingly, those that are most consumed. This includes analgesic and anti-inflammatory drugs, antibiotics, iodinated contrast media (for X-ray radiography), antidiabetics, antihypertensives/diuretic, $\beta$-blockers (for heart problems), lipid regulators (anticholesterol), psychiatric drugs, and antihistamines (e.g., gastric antiacid). ${ }^{32,37}$ Pharmaceuticals used for less common diseases (e.g., anticancer) or consumed at lower doses (e.g., contraceptive pills) are usually detected at lower concentrations $\left(<1-100 \mathrm{ng} \mathrm{L}^{-1}\right)$.

The fate of pharmaceuticals in WWTPs is very dependent on their characteristics, such as their sorption affinity and their biodegradability. Removal efficiency from 0 to $100 \%$ can be observed, depending on the compound (cf. Table 1). A few pharmaceuticals (e.g., some analgesic/antiinflammatory drugs, and natural hormones) are well removed during the biological treatment, but most are only partially or not removed at all. The majority of the drugs studied are on average removed less than $50 \%$. Pharmaceuticals have low volatility ${ }^{77}$ and thus are not expected to be stripped during the wastewater treatment. Removal by sorption can be significant (10-80\%) for a few hydrophobic or positively charged pharmaceuticals (e.g., mefenamic acid, fenofibrate, ofloxacin, norfloxacin, or ciprofloxacin). $35,74,76,97$ Most other pharmaceuticals have high solubility, low hydrophobicity, and often negative charge at neutral $\mathrm{pH}$ (acidic compounds), which means low sorption affinity on biological sludge (negatively charged). They are thus mostly found in 


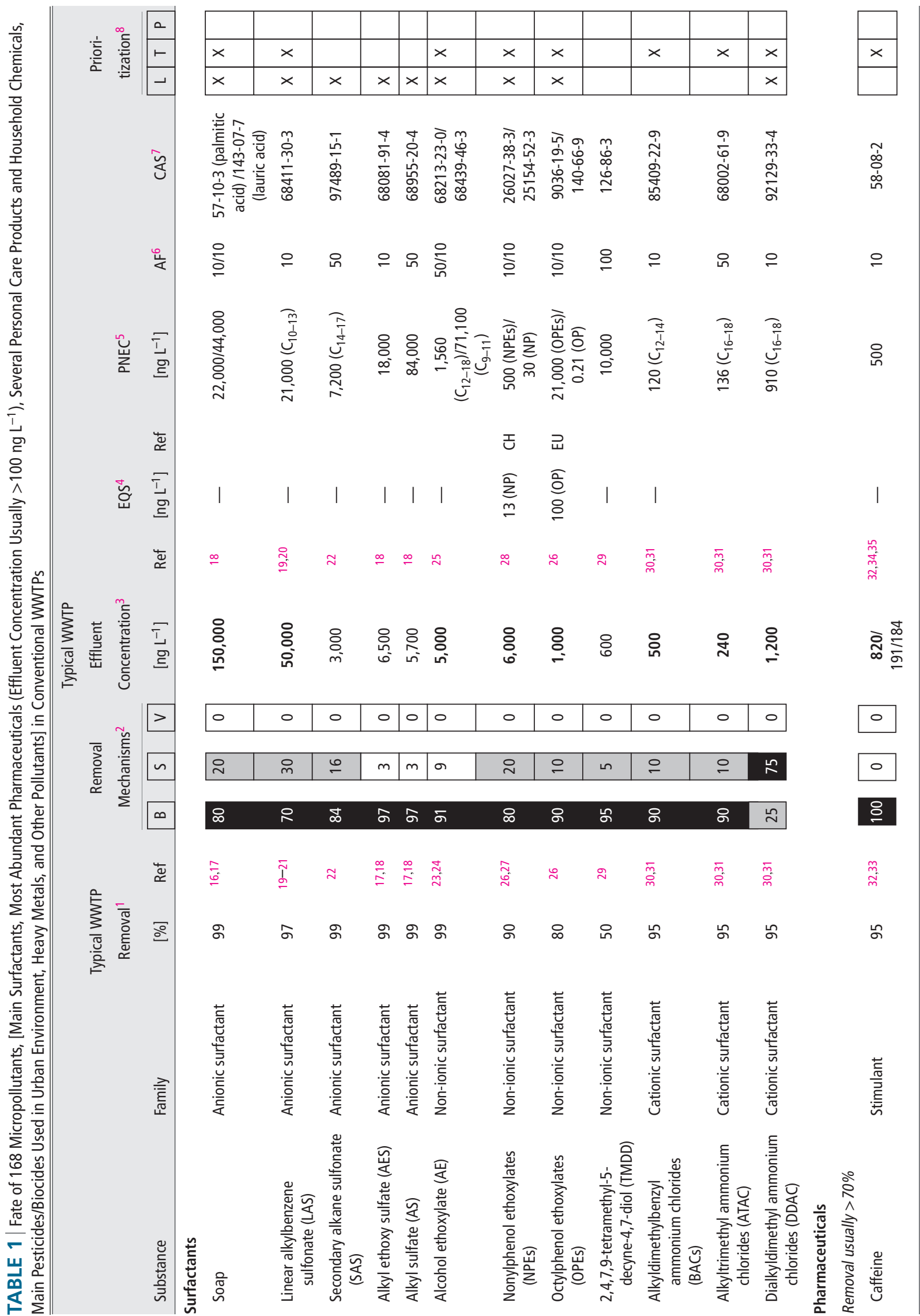




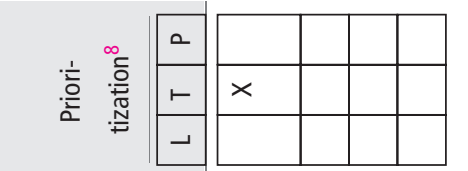

\begin{tabular}{|c|c|c|c|c|c|c|c|c|c|c|c|c|c|c|c|c|c|c|c|}
\hline$\times$ & $\times$ & $\times$ & & $\times$ & & $\times$ & $\times$ & & $\times$ & $\times$ & $\times$ & $\times$ & $\times$ & & & $\times$ & & $\times$ & $\times$ \\
\hline & $\times$ & $\times$ & $\times$ & $\times$ & & $\sim$ & $\times$ & $\sim$ & & & $\sim$ & $\sim$ & $\sim$ & $\sim$ & & & & & $\times$ \\
\hline & & & & & & & & & & $\times$ & $\times$ & $\times$ & & & & & $\times$ & & \\
\hline
\end{tabular}

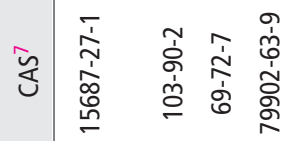

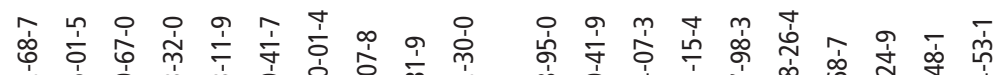

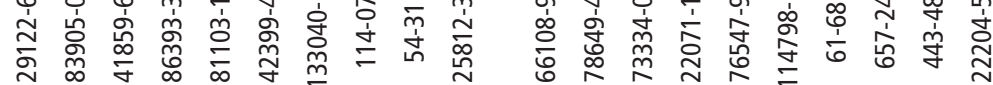

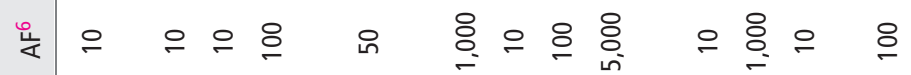

유 운 은응

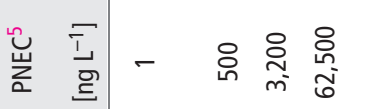

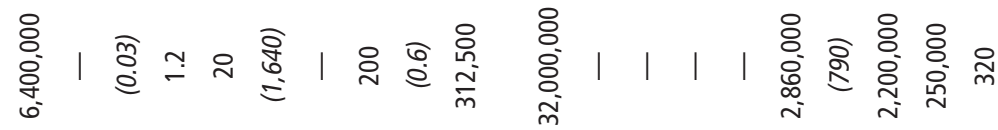

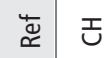

I I I I I I

エ I エ

芯省

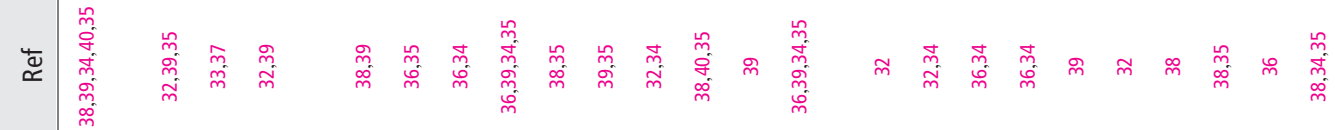

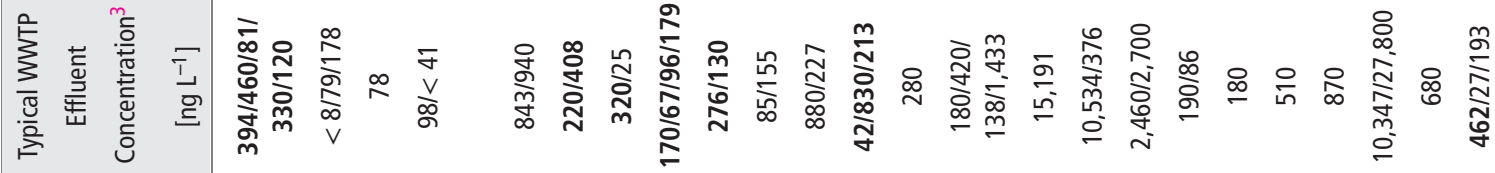

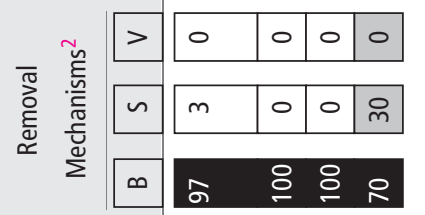

\begin{tabular}{|l|l|l|l|l|l|l|l|l|l|l|l|l|l|l|l|l|l|l|l|}
\hline 0 & 0 & 0 & 0 & 0 & 0 & 0 & 0 & 0 & 0 & 0 & 0 & 0 & 0 & 0 & 0 & 0 & 0 & 0 & 0 \\
\hline
\end{tabular}

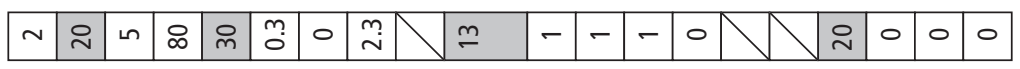

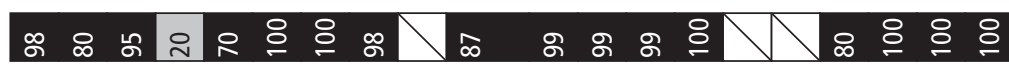

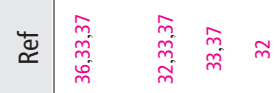

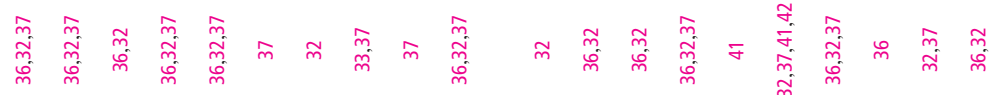

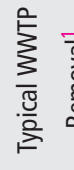

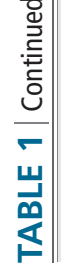

ஓ 용

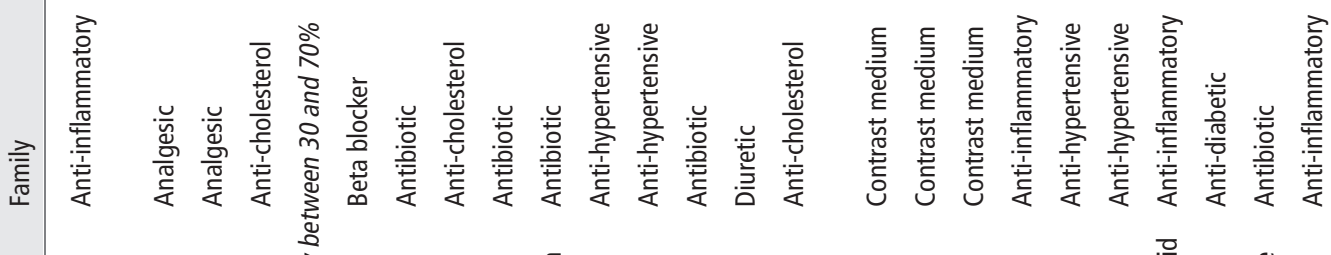

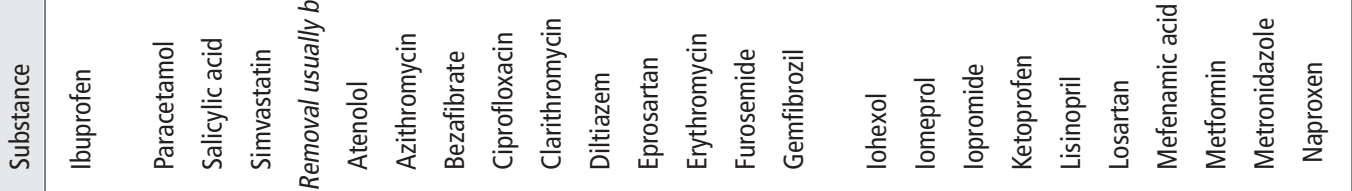




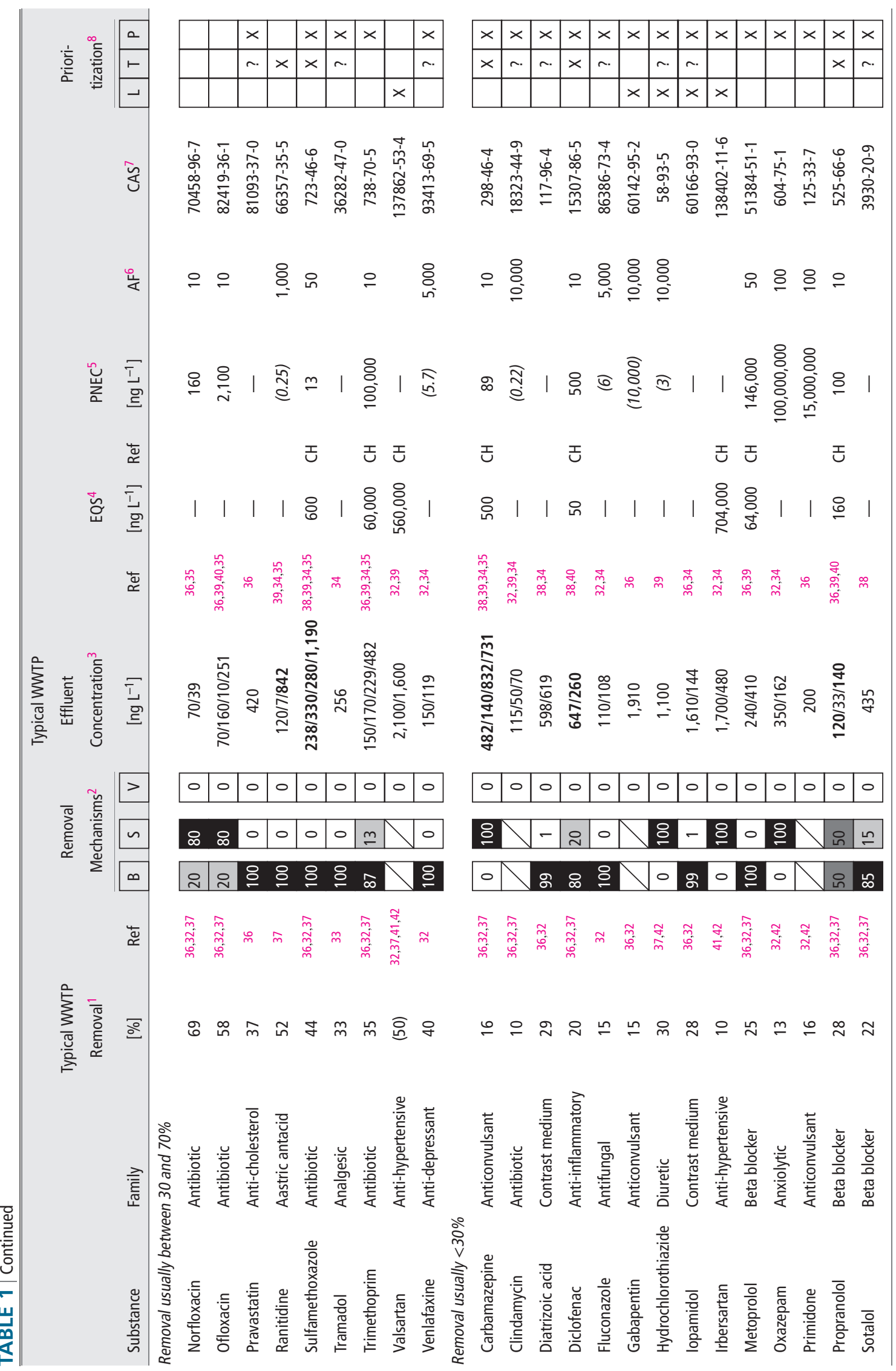




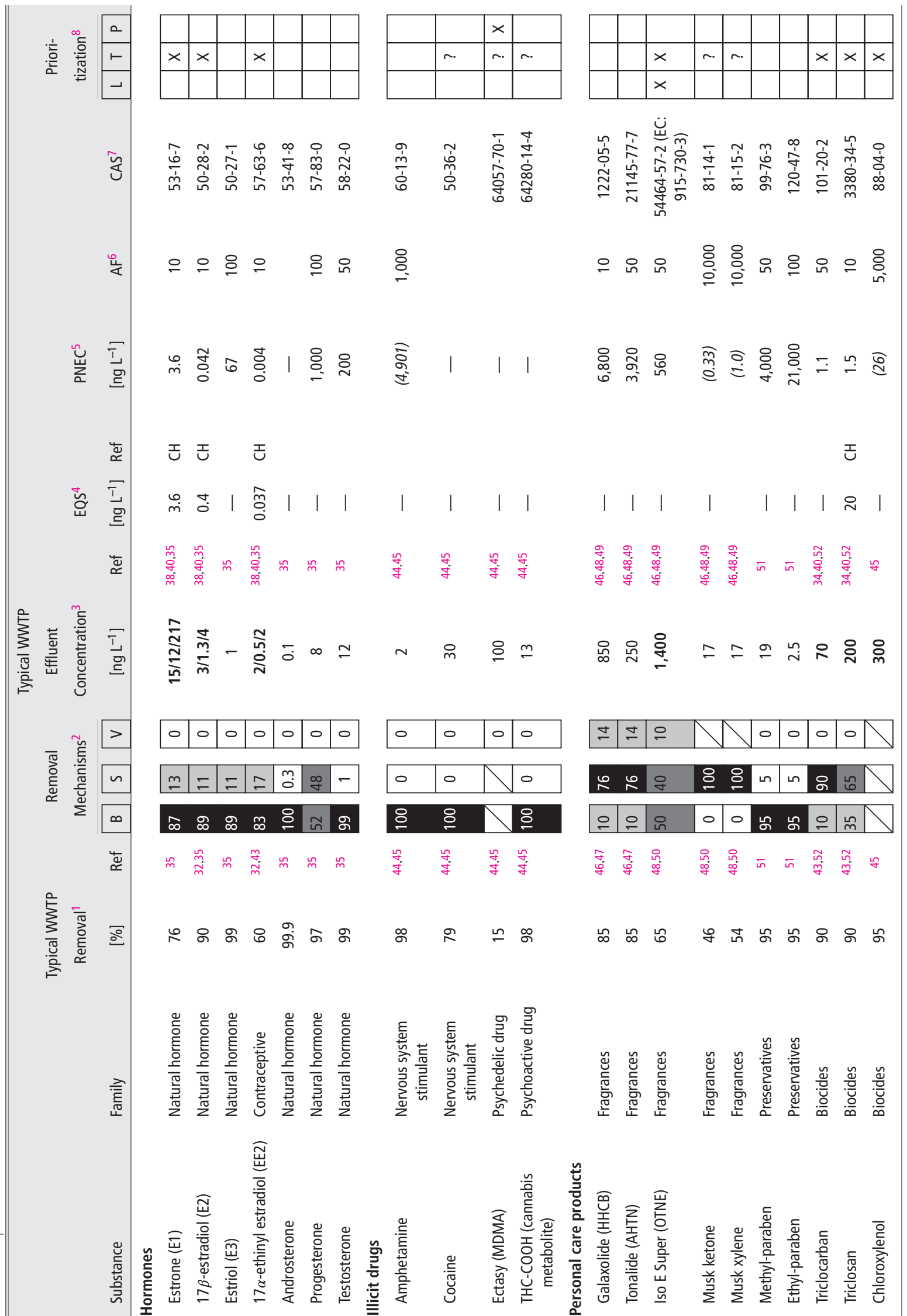




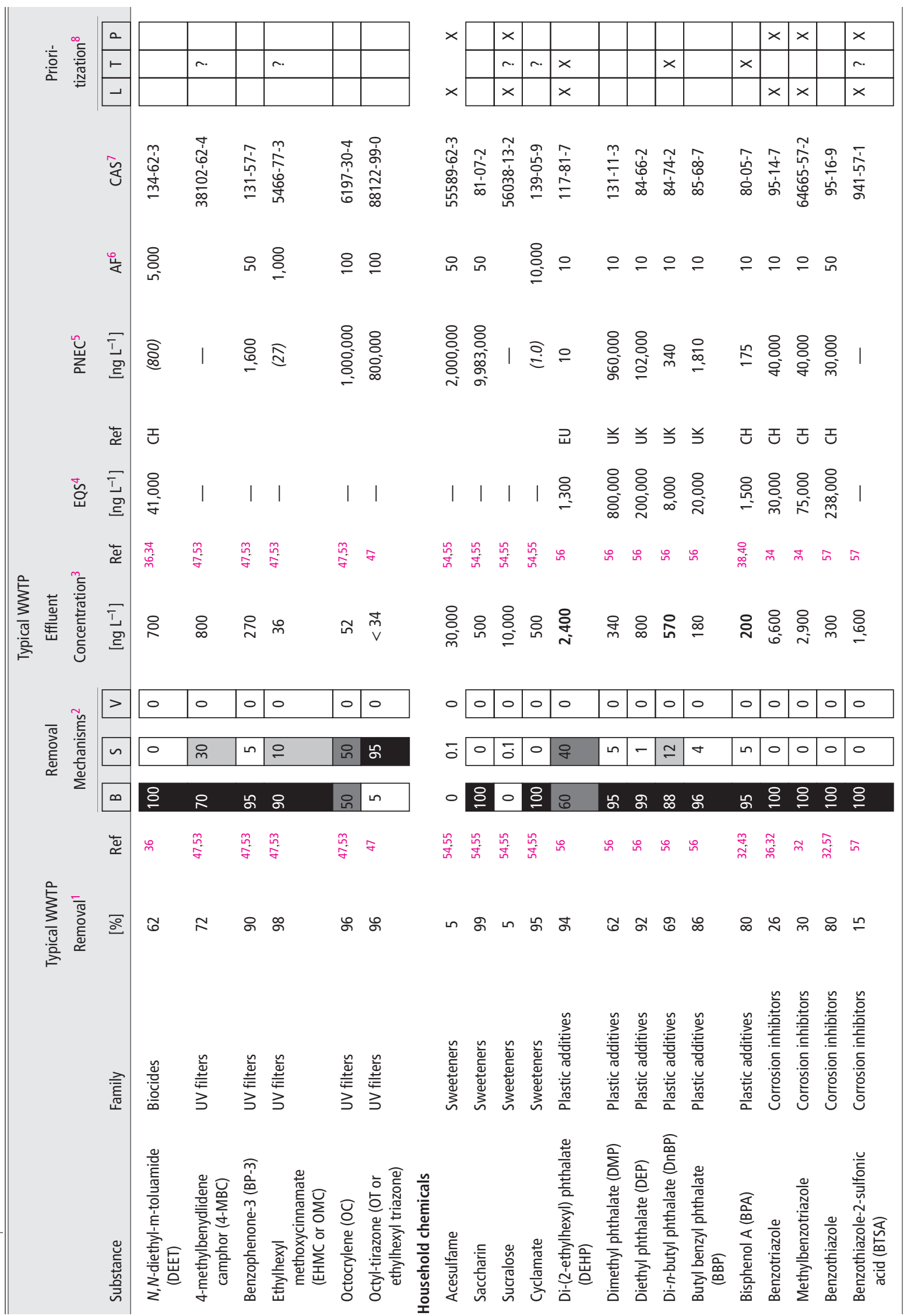




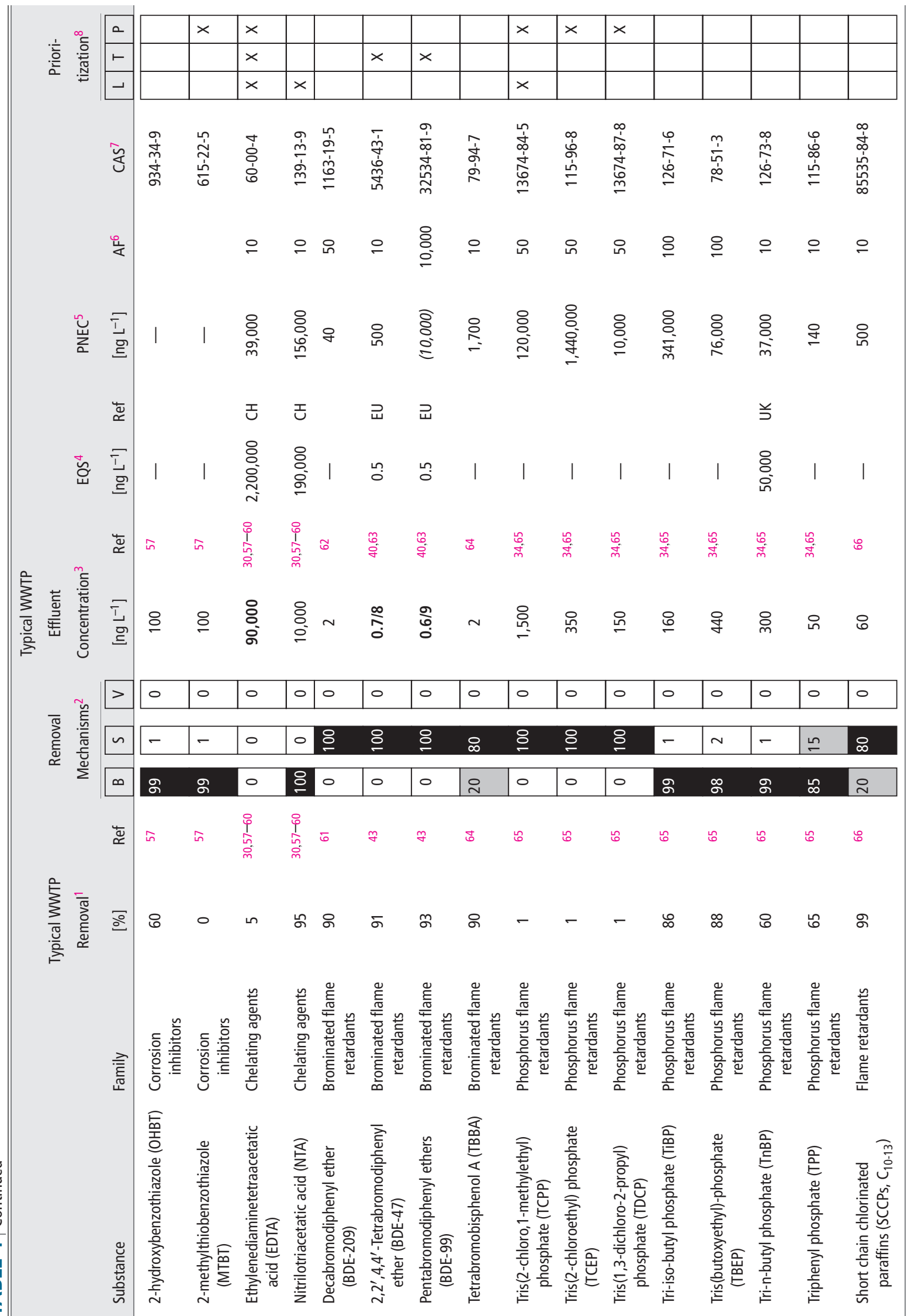




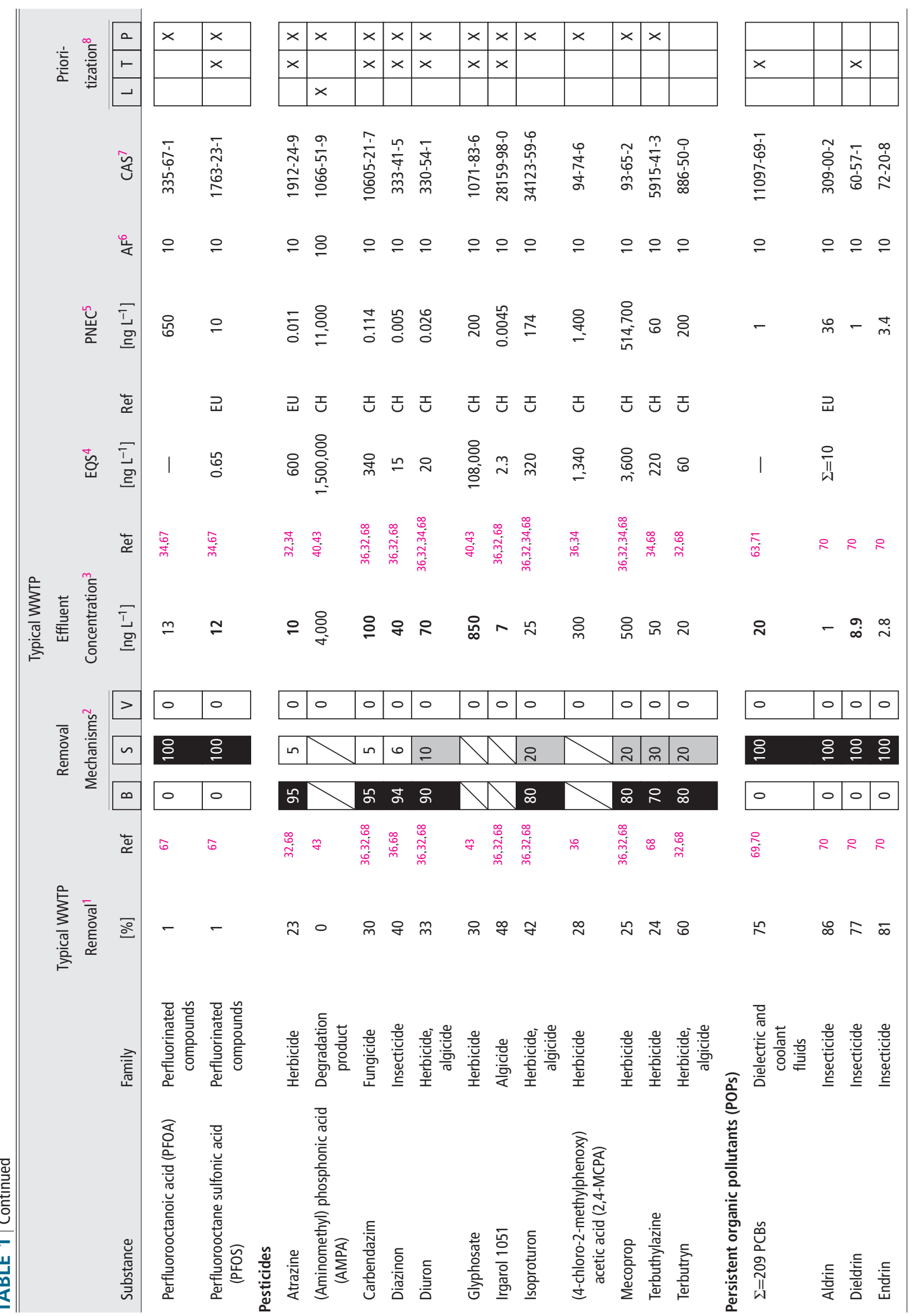




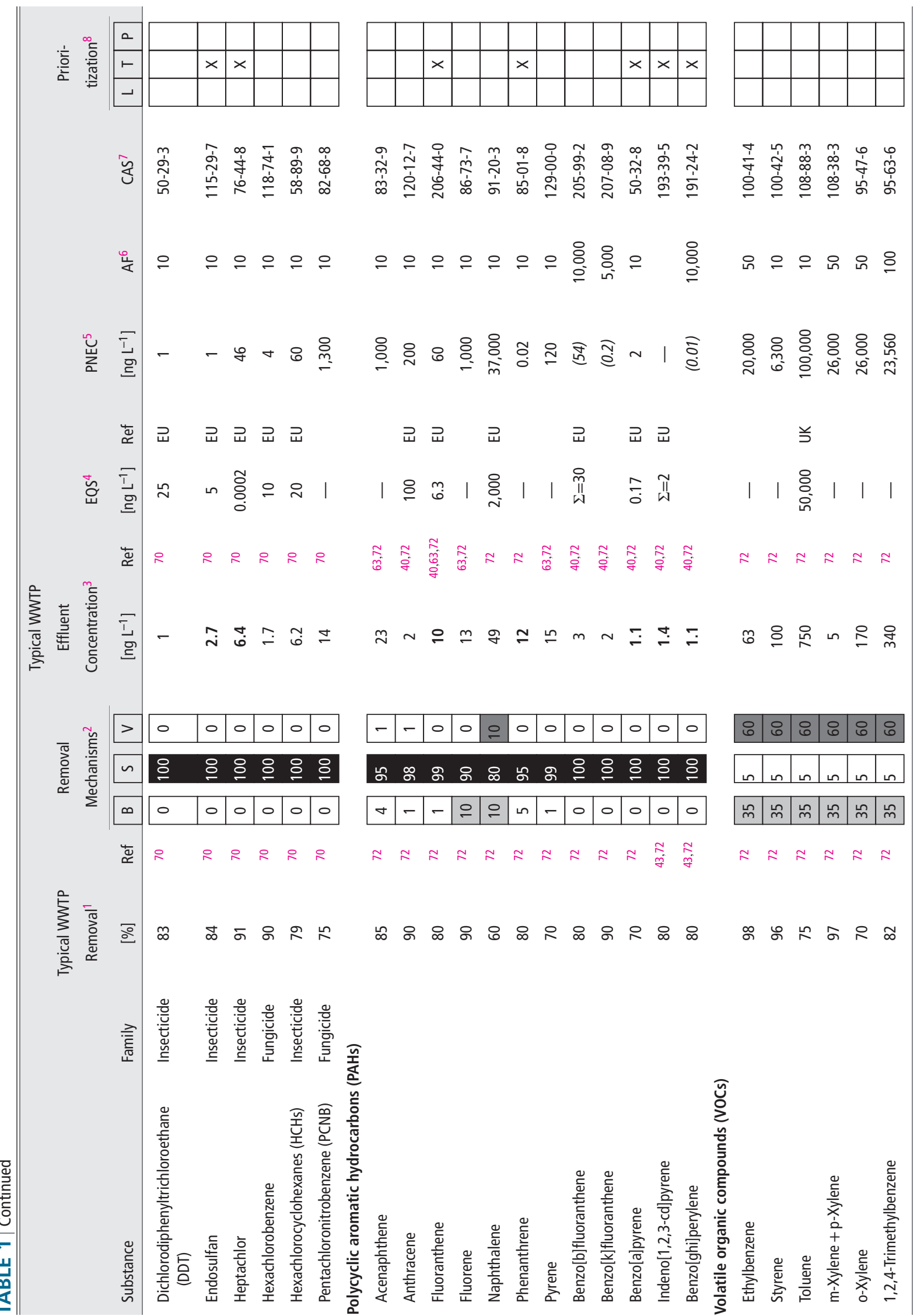




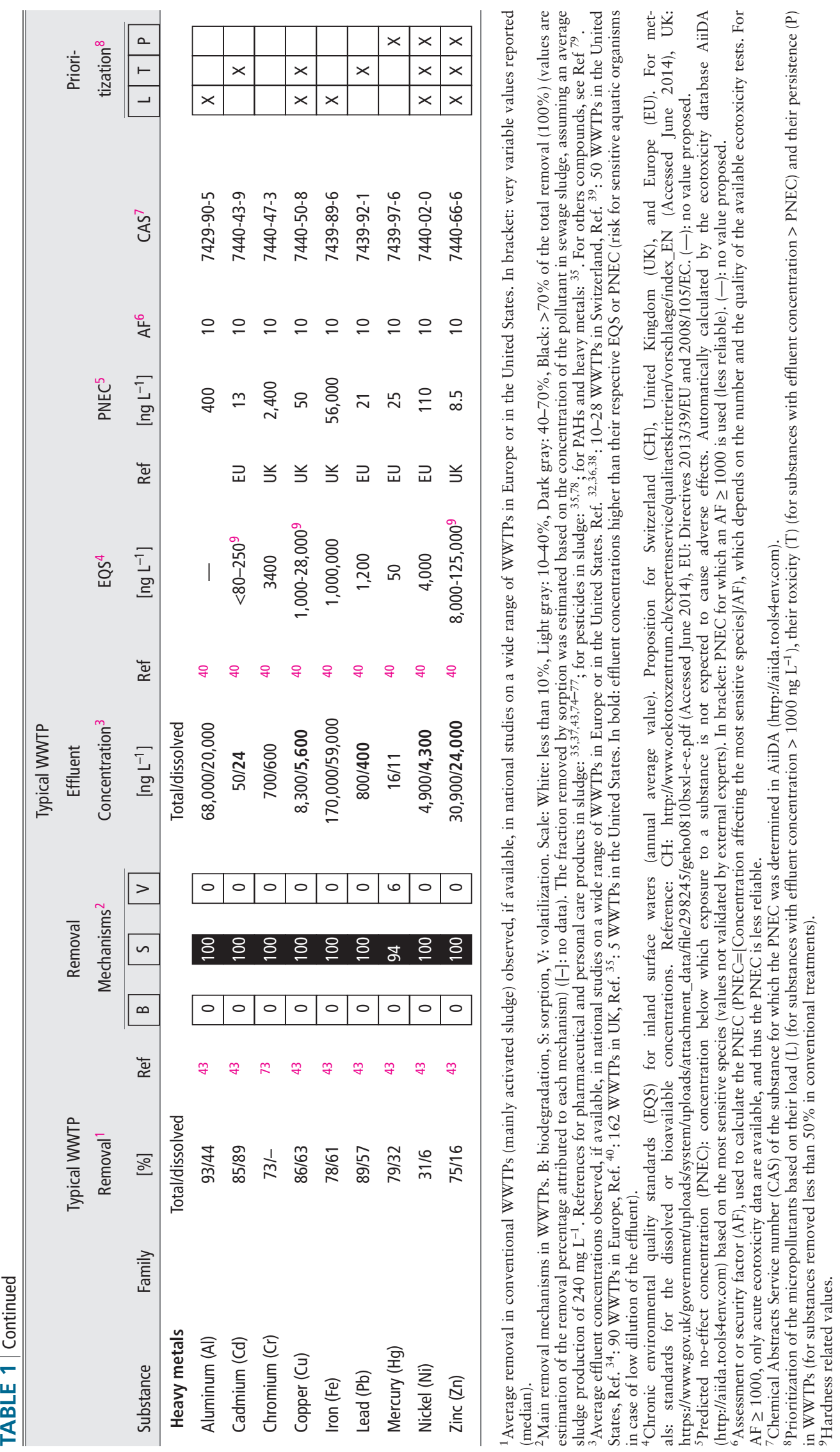


the 'dissolved' phase and their removal by sorption is often negligible $(<5 \%) .{ }^{37}$ Biodegradation or biotransformation is therefore the main removal mechanism for most pharmaceuticals.

Highly variable removal efficiencies are observed among different WWTPs for the same compound. ${ }^{37}$ Many authors have reported that better degradation of several drugs (such as hormones, ibuprofen, ketoprofen, naproxen, bezafibrate, gemfibrozil, atenolol, and some antibiotics) occurs in WWTPs with higher sludge retention time (SRT $>10$ days compared with 2 days). ${ }^{37}$ This was possibly because of the enrichment, at higher SRT, of certain microbial communities containing slow-growing organisms (such as autotrophic nitrifying bacteria), leading to more diverse enzymatic activity and metabolic pathways for the degradation of complex molecules. WWTPs incorporating nitrification, with thus longer SRT and hydraulic retention times (HRT), also showed better removal efficiencies for these compounds. ${ }^{32}$

The average concentrations of the most abundant pharmaceutical measured in WWTP effluents in various countries are usually between $<100 \mathrm{ng} \mathrm{L}^{-1}$ to a few $\mu \mathrm{g} \mathrm{L}^{-1}$ (Table 1). Concentrations can however vary strongly depending on the country (consumption habits) and the type of treatment. The risk for aquatic organisms generated by this mixture of pharmaceuticals at low concentrations, discharged permanently into receiving waters, is difficult to assess as the safety thresholds for many substances are not really known and the cocktail effect is difficult to evaluate. By comparison with their PNEC and EQS values (Table 1), a significant risk for the sensitive aquatic organisms in case of low dilution of the effluent $(<2-10$ times) may, however, be induced, for instance, by several antibiotics (azithromycin, ciprofloxacin, clarithromycin, erythromycin, sulfamethoxazole), antiinflammatory drugs (ibuprofen and especially diclofenac), carbamazepine, or propranolol. Despite their very low effluent concentrations, natural, and synthetic estrogens (estrone, estradiol, and ethinylestradiol) may also impact aquatic organisms (e.g., fish and mussel feminization or vitellogenin production in male) $)^{5,98}$ as they are still at levels more than 10 times above their respective EQS values for surface waters (Table 1).

Human pharmaceutical metabolites are frequently found in raw wastewater in the same range of concentrations (or even at higher levels) as the active pharmaceuticals (from $<10 \mathrm{ng} \mathrm{L}^{-1}$ up to $3-4 \mu \mathrm{g} \mathrm{L}^{-1}$ ). Human drug metabolites are usually more polar and hydrophilic than the parent compounds because of their transformation in the liver or kidney in order to be readily excreted in the urine or bile. ${ }^{96}$ They are thus not expected to be significantly removed by sorption. Some of these metabolites are well degraded during the biological treatment (e.g., $>90 \%$ for $N$-acetyl sulfamethoxazole), but many others are not. Human drug metabolites can thus be an issue in WWTP effluents (concentrations up to $1-4 \mu \mathrm{g} \mathrm{L}^{-1}$ ). $32,94,99,100$

Illicit drugs such as amphetamine, cocaine and its main metabolite benzoylecgonine, MDMA (ecstasy), or THC-COOH (cannabis metabolite) are present on average in the range of 100-2000 ng $\mathrm{L}^{-1}$ in raw wastewater, with the highest values usually observed in large cities and during weekends. ${ }^{44,45,101}$ These illicit compounds are on average well removed in conventional WWTPs (from $79 \%$ to > 98\%), except for MDMA (0-26\%). Concentrations of illicit drugs in the effluents are thus relatively low (Table 1). ${ }^{44,45,101}$

\section{Personal Care Products}

Personal care products (PCPs) include ingredients found in shampoos, washing lotions, skin care products, dental care products, sunscreen agents, cosmetics, perfumes, hair styling products, etc. The most studied PCPs are fragrances (such as polycyclic and nitro musks), ultraviolet (UV) filters, antimicrobial/disinfectants, preservatives, and insect repellents. Because of their wide consumption and their type of usage (often skin application), they enter municipal wastewater mainly via wash-off during showering or bathing. ${ }^{93}$

\section{Fragrances}

Fragrances such as synthetic musks are widely used in cosmetics, perfumes, body lotions, shampoos, detergents, and fabric softeners. The main synthetic musks detected in the environment are the polycyclic musks galaxolide (HHCB) and tonalide (AHTN), and the bicyclic hydrocarbon fragrance compound OTNE. ${ }^{47,102}$ Concentrations of these musks in raw wastewaters are usually around $0.5-13 \mu \mathrm{g} \mathrm{L^{-1 }}$ for HHCB, AHTN, and OTNE. ${ }^{46,47,48,49,103}$ Because of their hydrophobicity $\left(\log K_{\mathrm{OW}}>5\right)$, they are usually well removed in WWTPs, from 60 to $99 \%$, mainly by sorption. ${ }^{46,47,48,50,104}$ Because of their relative volatility, a fraction of AHTN and HHCB (up to $14 \%$ ) volatilizes from the aeration basins, leading to the presence of relatively high concentrations of musks (up to $300 \mu \mathrm{g} \mathrm{m}^{-3}$ air for HHCB) in the indoor atmosphere of WWTPs. ${ }^{105,106}$ Concentrations of fragrances in WWTP effluents are usually reported in the range of $250-1300 \mathrm{ng} \mathrm{L}^{-1}$ for HHCB, AHTN, and OTNE (Table 1). Because of their lipophilicity, polycyclic musks can then bioconcentrate in fish. The 
average concentration of HHCB found in fish filets in the United States was at $1100 \mathrm{ng} \mathrm{g}^{-1}$ tissue. ${ }^{107}$

\section{Preservatives, Antimicrobials, and Insect Repellents}

Parabens are widely employed as antimicrobial preservatives in PCPs such as body lotions, shampoos, tooth pastes, deodorants, etc. The most commonly used parabens include methyl- (MeP), ethyl- (EtP), propyl- (PrP), butyl- (BuP), and benzyl-parabens $(\mathrm{BzP})$. Because of their light estrogenic effect and their ubiquitous presence in human tissues, they are possibly substances of concern for human health. ${ }^{108}$ Median concentrations of parabens in raw municipal wastewater in Spain vary from less than $2 \mathrm{ng} \mathrm{L}^{-1}$ for BzP up to $2500 \mathrm{ng} \mathrm{L}^{-1}$ for MeP. ${ }^{51}$ Parabens are well $(>95 \%)$ removed in WWTPs, mainly by biodegradation, leading to concentrations in the effluent $(<100$ ng $\mathrm{L}^{-1}$ ) below their PNEC (Table 1).

Antimicrobial agents are widely used in PCPs, mainly in soaps (liquids and bars), toothpastes, deodorants, and shave gels. Triclocarban and especially triclosan are among the most common antimicrobials used. Their concentrations in raw wastewater are relatively high, on average between 1 and $10 \mu \mathrm{g} \mathrm{L}^{-1}$ for triclosan and slightly lower for triclocarban $\left(0.1-6 \mu \mathrm{g} \mathrm{L}^{-1}\right) \cdot{ }^{43,52,109}$ Because of their hydrophobicity $\left(\log K_{\mathrm{OW}}\right.$ around 4.9$)$, they are usually well removed $(>80 \%)$ in WWTPs, mostly by sorption onto sludge. ${ }^{43,52}$ Their concentrations in WWTP effluents are reported to be around 70-200 ng $\mathrm{L}^{-1}$, which for example exceed the proposed Swiss EQS and their respective PNECs (Table 1). The impact of these compounds on sensitive organisms can thus not be excluded in case of low effluent dilution.

Chloroxylenol is another antibacterial agent found at high concentrations in raw wastewater $\left(10-30 \mu \mathrm{g} \mathrm{L}^{-1}\right)$. Despite good removal $(>95 \%)$ in WWTPs, its concentration in effluent was reported to be around $300 \mathrm{ng} \mathrm{L}^{-1} .{ }^{45}$

$N, N$-diethyl- $m$-toluamide (DEET) is the active ingredient of most commercial insect repellents. Showering and bathing after application and laundering of clothes are considered to be a major source of DEET in wastewater. Concentrations in raw wastewater are in the range of $0.1-10 \mu \mathrm{g} \mathrm{L}^{-1}$, with the highest values observed usually in summer. ${ }^{110}$ Removal efficiency of DEET in WWTPs is highly variable, ranging from 10 to $99 \%$ depending on the plant or season. Due to its low sorption affinity and low volatility, ${ }^{110,111}$ the main removal mechanism is expected to be biodegradation. Average concentrations of DEET in WWTP effluents are between 100 and 900 ng L ${ }^{-1}$ in Europe, ${ }^{34,36,110}$ which is far below the proposed EQS value (Table 1).

\section{UV Filters}

Organic UV filters are widely used in sunscreen agents and cosmetics to protect against sunburn or as a preservative to prevent UV degradation of other cosmetics ingredients. They mainly enter aquatic environments either directly during recreational activity (bathing in lakes and rivers) or indirectly through municipal wastewater (wash-off from the skin during showering). Many (about 30) different UV filters are frequently used. Some of the most common are benzophenone-1, -3 (also called oxybenzone), and -4 (BP-1, BP-3, BP-4), 4-methylbenydlidene camphor (4-MBC), ethylhexyl methoxy cinnamate [EHMC, also called octyl-methoxycinnamate $(\mathrm{OMC})$, octocrylene (OC), octyl-triazone (OT), and butyl methoxydibenzoylmethane (BMDM). ${ }^{47,53,112}$ Concentrations of UV filters in Swiss raw wastewater vary seasonally, from $<100 \mathrm{ng} \mathrm{L}^{-1}$ up to $20 \mu \mathrm{g}$ $\mathrm{L}^{-1}$, with usually higher concentrations after sunny summer days (1-10 $\mu \mathrm{g} \mathrm{L}^{-1}$ for 4-MBC, BP-3, EHMC, OT and OC)..$^{47,53}$ Most UV filters (e.g., BP-3, EHMC, OC, OT) are usually over $90 \%$ removed in conventional WWTPs (Table 1). ${ }^{47,53}$ Some UV filters (such as OC or OT) are lipophilic as they are often used as additives in cosmetics (usually composed of lipids or oils). They tend then to sorb onto particles and are usually partially (50-95\%) removed by sorption. Because of their biodegradability, most UV filters are further removed by degradation. ${ }^{47}$ Concentrations in WWTPs effluents are thus reduced and usually in the range of $10 \mathrm{ng} \mathrm{L}^{-1}$ to $1 \mu \mathrm{g} \mathrm{L}^{-1},{ }^{53}$ which is lower than their respective PNECs (Table 1).

\section{Household and Industrial Chemicals}

Many other chemicals are used daily in homes or workplaces (sweeteners, anticorrosives or chelating agents) or are present in household equipment (plasticizers, flame retardants, perfluorinated compounds). They often find their way into sewers.

\section{Food and Beverage Additives}

Artificial sweeteners such as acesulfame, aspartame, cyclamate, neotame, neohesperidine dihydrochalcone (NHDC), saccharin, and sucralose, are widely used (increasing over time) in food, beverages, and toothpaste, where they act as sugar substitutes. Artificial sweeteners are designed not to be metabolized in the human body (their goal is to provide a negligible energy source). Thus, except for aspartame, neotame and NHDC, which are mostly excreted in metabolite forms, $90-100 \%$ of all other sweeteners consumed are then released in urine and feces. The estimated total load of sweeteners in sewers is around $10-60 \mathrm{mg}$ 
day $^{-1}$ capita $^{-1}, 55$ which is in the same range as the total load of pharmaceuticals. Concentrations of acesulfame, cyclamate, saccharin, and sucralose in raw municipal wastewaters are relatively high, with average concentrations around 20-30 $\mu \mathrm{g} \mathrm{L}^{-1} .54,55$ Cyclamate and saccharin are easily biodegradable and are removed from 90 to more than $99 \%$ in WWTPs, leading to concentrations typically below $1 \mu \mathrm{g} \mathrm{L}^{-1}$ in effluents. Acesulfame and sucralose are, on the contrary, very persistent and not significantly removed during treatment. Their concentrations in effluents are therefore relatively high (10-50 $\mu \mathrm{g} \mathrm{L}^{-1}$ for acesulfame and 0.4-20 $\mu \mathrm{g} \mathrm{L}^{-1}$ for sucralose) (Table 1). ${ }^{54}$ Sweeteners are not expected to be toxic to aquatic organisms at these concentrations, ${ }^{113}$ but they may contaminate drinking water resources. Indeed, sweetener concentrations are among the highest concentrations of anthropogenic trace pollutants found in drinking water (up to $7 \mu \mathrm{g} \mathrm{L}^{-1}$ for acesulfame). These levels are, however, around 1000 times lower than their organoleptic (sweetness) threshold values. ${ }^{55}$

\section{Plasticizers and Plastic Additives}

Plasticizers are added in plastics to improve their flexibility. Phthalates (phthalic acid esters) are common plasticizers, although phthalates are also used as fragrance dispersants in cosmetic products (e.g., air fresheners), or as additives in epoxy resins, food packaging, building materials, etc. Phthalates are pollutants of concern due to their disruption of endocrine activity and their association with many human health problems (alteration of reproduction, development and neurodevelopment). ${ }^{114}$ The most studied phthalates are di-(2-ethylhexyl) phthalate (DEHP) (widely used as PVC plasticizer, for instance in PVC shower curtains), dimethyl phthalate (DMP) and diethyl phthalate (DEP) (used as fragrance dispersants), and di- $n$-butyl phthalate (DnBP) and butyl benzyl phthalate (BBP) (used as an additive in many products). Because of their widespread use, median concentrations of phthalate in raw municipal wastewater are relatively high, around $40 \mu \mathrm{g} \mathrm{L}^{-1}$ for DEHP, $10 \mu \mathrm{g} \mathrm{L}^{-1}$ for DEP and $1-2 \mu \mathrm{g} \mathrm{L}^{-1}$ for DMP, DnBP, and BBP. Phthalates are partially to well removed (60-95\%) in WWTPs, partly by sorption but mainly by biodegradation (Table 1). Median concentrations in WWTP effluents were reported to be around $2.4 \mu \mathrm{g}$ $\mathrm{L}^{-1}$ for DEHP and between 200 and $800 \mathrm{ng} \mathrm{L}^{-1}$ for DMP, DEP, DnBP, and BBP. ${ }^{56}$ In case of low dilution of the effluent, a risk for aquatic organisms cannot be excluded as DEHP may exceed its EQS and DnBP its PNEC (Table 1).

Bisphenol A (BPA) is a plastic additive mainly used (about 95\%) in the production of synthetic polymers such as polycarbonates (transparent hard plastic) and epoxy resins. These polymers are widely used in households, for instance for inner water-pipe coating, food containers, bottles, inner coatings for tins (canned food) and beverage cans, toys, etc. BPA is also used as a stabilizer in PVC (e.g., in shower curtains) and as a color developer in thermal papers (e.g., shop receipts, faxes). ${ }^{115}$ Recycling of thermal paper was reported to contaminate recycled papers with BPA. Up to $46 \mu \mathrm{g} \mathrm{g}^{-1}$ (average $19 \mu \mathrm{g} \mathrm{g}^{-1}$ ) of BPA was found in recycled toilet paper, ${ }^{116}$ which may contribute significantly to the load of BPA in wastewater. BPA was found on average at $0.8-1 \mu \mathrm{g}$ $\mathrm{L}^{-1}$ in raw wastewater in Europe. ${ }^{32,43} \mathrm{BPA}$ is usually well removed $(>80 \%)$, mostly by biodegradation, in WWTPs, especially in those that have a nitrification step. ${ }^{32,43}$ BPA concentrations in WWTPs effluents were reported on average at around 100-300 ng $\mathrm{L}^{-1} \cdot{ }^{40,38} \mathrm{BPA}$ is an endocrine disrupter and can affect fish (impact on gonad morphology) at very low concentrations $\left(1 \mu \mathrm{g} \mathrm{L}^{-1}\right),{ }^{117}$ with a PNEC of $175 \mathrm{ng} \mathrm{L}^{-1}$ (Table 1). A risk for aquatic organisms can thus not be excluded in case of low effluent dilution.

\section{Anticorrosives}

Benzotriazoles are high-production-volume polar chemicals mostly used as corrosion inhibitors in de-icing fluids for aircrafts, automotive antifreeze formulation, brake fluids, industrial cooling systems, but also in households for silver protection and as a polishing agent in dishwashing detergents. The main benzotriazoles reported are benzotriazole $(\mathrm{BTr})$ itself, and 4- and 5-methylbenzotriazoles (MBTr). Because of their wide usage in dishwashing products (on average $12.5 \mathrm{mg}$ per tablet), it was estimated that around $3 \mathrm{mg} \mathrm{d}^{-1}$ capita $^{-1}$ of benzotriazoles are released in the sewers. ${ }^{118}$ Concentrations of benzotriazoles in raw wastewater are thus relatively high, on average around $10 \mu \mathrm{g} \mathrm{L}^{-1}$ (usually between 5 and $15 \mu \mathrm{g} \mathrm{L}^{-1}$ ) for BTr and around $5 \mu \mathrm{g} \mathrm{L}^{-1}$ for MBTr. Removal of benzotriazoles in WWTPs is usually low, on average between 20 and $30 \%$. Concentrations of benzotriazoles in WWTP effluents are therefore relatively high $\left(2-7 \mu \mathrm{g} \mathrm{L}^{-1}\right)$ but still far below their EQS values (cf. Table 1).

Benzothiazoles are also high-production-volume chemicals with various applications, the main one being vulcanization accelerators in rubber, but they are used also as corrosion inhibitors in antifreeze and cooling liquids, in wood preservation or in industrial processes. The main benzothiazoles reported in municipal wastewater, coming from urban runoff (tire abrasion on roads) and unknown sources in households, were benzothiazole-2-sulfonic acid (BTSA), benzothiazole (BT), 2-hydroxybenzothiazole (OHBT), 
and 2-methylthiobenzothiazole (MTBT). Their individual concentrations in raw wastewater and in WWTP effluents are in the range of $0.2-2 \mu \mathrm{g} \mathrm{L}^{-1}$, which are much lower than the proposed Swiss EQS value for surface waters $\left(238 \mu \mathrm{g} \mathrm{L}^{-1}\right){ }^{119}$ Removal efficiencies reported for benzothiazoles in WWTPs are very variable, from 0 to $80 \%$, mostly because of biotransformation/degradation (Table 1). ${ }^{57,120-122}$

\section{Synthetic Chelating Agents}

Ethylenediamine tetraacetatic acid (EDTA) and nitrilotriacetatic acid (NTA) are synthetic chelating agents designed to 'sequester' metal ions such as $\mathrm{Fe}^{3+}, \mathrm{Ca}^{2+}$ or $\mathrm{Mg}^{2+}$. EDTA and NTA are widely used in laundry and household detergents as builders to reduce water hardness $\left(\mathrm{Ca}^{2+}, \mathrm{Mg}^{2+}\right)$, or as stabilizers in personal care products and detergents. Both compounds are very hydrophilic and with a low volatility. EDTA and NTA are found at very high concentrations in raw municipal wastewater, with average concentrations between 70 and $950 \mu \mathrm{g}$ $\mathrm{L}^{-1} \cdot 30,43,58$ NTA is biodegradable with good removal efficiencies (90-97\%) reported for WWTPs. EDTA is, on the contrary, not biodegradable, and less than $10 \%$ removal is usually reported. Concentrations of chelating agents in WWTP effluents are on average around 3-50 $\mu \mathrm{g} \mathrm{L}^{-1}$ for NTA and around $50-130 \mu \mathrm{g}$ $\mathrm{L}^{-1}$ for EDTA. ${ }^{30,57,58-60}$ EDTA has therefore one of the highest (together with some surfactants) average concentrations reported for synthetic chemicals in municipal WWTP effluents. These concentrations are however lower than the proposed EQS values. EDTA concentrations in effluents surpass the relevant PNEC (39 $\mu \mathrm{g} \mathrm{L} \mathrm{L}^{-1}$, Table 1$)$ and thus potential impacts of this compound cannot be neglected.

\section{Flame Retardants}

Flame retardants are chemicals incorporated in various household equipment, such as building materials (e.g., insulation), electrical/electronic devices, upholstered furniture (e.g., sofas), textiles, plastics, or polyurethane foams, to inhibit fires. The main families of organic flame retardants are based on brominated, organophosphorus, and chlorinated paraffin compounds. ${ }^{123}$ Flame retardants can reach the sewers during cleaning of textiles or household surfaces (flame retardants can accumulate in dust).

Brominated flame retardants have been used for several decades but, due to their environmental persistence, bioaccumulative potential and toxicity, some congeners of polybrominated biphenyls (PBBs) (hexa-BB) and polybrominated diphenyl ethers (PBDEs) (tetra-, penta-, hexa-, and hepta-BDEs) were classified in 2009 as persistent organic pollutants
(POPs) in the Stockholm Convention. ${ }^{123}$ Their use is now restricted in many countries, but due to their presence in high quantities in existing furniture and electric devices, they are expected to continue to contaminate the environment for many years.

PBDEs are a family of 209 congeners (not all used in commercial mixtures) with a structure similar to the toxic polychlorobiphenyls (PCBs). ${ }^{124}$ The congeners BDE-47, $-99,-100,-153$, and -209 are the most frequently detected in wastewater. ${ }^{62}$ Median concentrations of BDE-47, -99, and -209 in raw wastewater were reported to be between 10 and $140 \mathrm{ng} \mathrm{L^{-1 }}$ in Europe. ${ }^{43,61}$ PBDEs are usually well removed (median removal around 90\%) in conventional WWTPs, mostly during secondary treatments. ${ }^{43}$ As they are poorly biodegradable and relatively hydrophobic $\left(\log K_{\text {OW }} 4-10\right)$, the main removal mechanism is sorption onto sludge. Concentrations of PBDEs in WWTP effluents are dominated by congeners BDE-47 and -99, found at a median concentrations around $9 \mathrm{ng} \mathrm{L}^{-1}$ in the US (52 WWTPs) and $0.7 \mathrm{ng} \mathrm{L}^{-1}$ in the UK (162 WWTPs). ${ }^{40,63}$ Despite these very low concentrations (sum of PBDEs usually lower than $\left.30 \mathrm{ng} \mathrm{L}{ }^{-1}\right),{ }^{62}$ PBDEs may bioaccumulate in aquatic organisms at levels much higher (e.g., average 30-200 $\mu \mathrm{g} \mathrm{kg}^{-1}$ wet weight in fish from the St. Lawrence River) ${ }^{125}$ than the European EQS for biota (8.5 $\mathrm{ng} \mathrm{kg}^{-1}$ wet weight). ${ }^{126}$

Other brominated flame retardants (BFRs) such as tetrabromobisphenol A (TBBA) are still widely used. TBBA was found on average at around $20 \mathrm{ng}$ $\mathrm{L}^{-1}$ in wastewater and is reported to be well removed $(>90 \%)$ in WWTPs, probably by a combination of sorption and biotransformation, leading to effluent concentrations $<2$ ng L ${ }^{-1} .{ }^{64}$ Many new BFRs are now also emerging due to the ban of several PBDE congeners. ${ }^{127}$ Concentrations and fate of these new BFRs in WWTPs are still little studied, but it seems that concentrations of most of them are still below 10 ng $\mathrm{L}^{-1}$ in raw wastewater. ${ }^{61}$

Organophosphorus flame retardants (OFRs) are, after BFRs, the second most consumed organic flame retardants. ${ }^{128}$ They were proposed as an alternative to BFRs, and their consumption is expected to increase. ${ }^{129,130}$ They are also commonly used as plasticizers, lubricants, hydraulic fluids, floor polish, or concrete additives $(0.002 \%$ $\mathrm{w} / \mathrm{w}$ as antifoam). ${ }^{129,130}$ The most frequently detected organophosphorus flame retardants and plasticizers are the non-chlorinated trimethyl phosphate (TMP), tri- $n$-butyl phosphate (TnBP), tri-iso-butyl phosphate (TiBP), tris(butoxyethyl)-phosphate (TBEP), triphenyl phosphate (TPP), and 2-ethylhexyl diphenyl phosphate (EHDPP), and the chlorinated 
tris(1,3-dichloro-2-propyl) phosphate (TDCP), tris(2-chloro,1-methylethyl) phosphate (TCPP), and tris(2-chloroethyl) phosphate (TCEP). All these compounds were present in raw municipal wastewater at average concentrations from $100 \mathrm{ng} \mathrm{L}^{-1}$ up to $19 \mu \mathrm{g} \mathrm{L}^{-1}$, which is much higher than reported for brominated flame retardants. The highest average concentrations were observed for TnBP and TiBP (1-19 $\left.\mu \mathrm{g} \mathrm{L}^{-1}\right)$, plasticizers used also as antifoam in concrete from where they may leach in the sewers ${ }^{129}$; TBEP (4-13 $\left.\mu \mathrm{g} \mathrm{L}^{-1}\right)$, a plasticizer and floor polish; and TCPP (1-4 $\left.\mu \mathrm{g} \mathrm{L}^{-1}\right)$, a flame retardant mostly used in polyurethane foam and building insulation. ${ }^{65,131}$ TiBP and TBEP are usually well removed in WWTPs $(>80 \%)$, probably by a combination of sorption onto secondary sludge and biotransformation, whereas TnBP and TPP have removal efficiencies between 50 and $75 \%$. The chlorinated TCPP, TCEP, and TDCP are not significantly $(<5 \%)$ removed in WWTPs. ${ }^{65}$ Concentrations of OFRs in WWTP effluents are thus still relatively high, with average values observed between $50 \mathrm{ng} \mathrm{L}^{-1}$ for TPP, up to $0.5-10 \mu \mathrm{g} \mathrm{L}^{-1}$ for TCPP and TBEP (Table 1). ${ }^{34,65,131}$ ORFs were among the most relevant substances detected in the effluents of 90 European WWTPs. ${ }^{34}$ It is not expected that the levels of OFRs found in effluents generate impacts on aquatic organisms as they are much lower than their PNECs (Table 1). But several OFRs (TCEP, TCPP, TDCP, and TBEP) are carcinogens or possible carcinogens, and some are neurotoxic and/or can accumulate in liver and kidneys. ${ }^{123}$ It is therefore not desirable to release them into the environment.

Chlorinated paraffins (CPs) are the third most consumed family of organic flame retardants. ${ }^{128} \mathrm{CPs}$ are also used as plasticizers or as additives in paints or sealants. Short chain CPs (SCCPs, $\mathrm{C}_{10-13}$ ) have received growing global attention in recent years for their long-range transport, persistence in the environment, bioaccumulation, and potential toxicity to aquatic organisms. Their presence in raw municipal wastewater is little studied but average concentrations (sum of $\mathrm{C}_{10}$ to $\mathrm{C}_{13}$ chain lengths) around $6 \mu \mathrm{g} \mathrm{L} \mathrm{L}^{-1}$ were reported in Beijing, China. SCCPs seem to be well removed (total removal $>99 \%$ ) in WWTPs, 70-80\% by sorption and elimination with the sludge and $20-30 \%$ probably by biotransformation/degradation. Final effluent concentrations of SCCPs (sum of $\mathrm{C}_{10}$ to

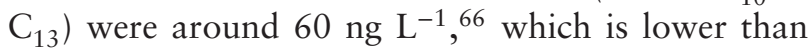
the PNEC (500 ng L ${ }^{-1}$, Table 1). In Europe, lower CPs concentrations were found in raw wastewater, on average (15 WWTPs) $140 \mathrm{ng} \mathrm{L}^{-1}$ for the sum of $\mathrm{C}_{10-13}, 841$ ng $\mathrm{L}^{-1}$ for $\mathrm{C}_{14-16}$ and $650 \mathrm{ng} \mathrm{\textrm {L } ^ { - 1 }}$ for $\mathrm{C}_{17-28}$, almost completely associated with suspended solids. CPs were not detected in the effluent. ${ }^{132}$

\section{Perfluorinated Compounds}

Perfluorinated compounds (PFCs) are a large family of synthetic chemicals used in many types of household products that utilize their properties of creating water-repellent, grease-repellent, and dirt-repellent surfaces. They are for instance used in nonstick cookware (polytetrafluoroethylene (PTFE) known as Teflon), water-proofing sprays, Gore-Tex clothing, stain- or water-resistant textiles (clothes, carpets, tablecloths, upholstered furniture), some cosmetics (nail polish, eye make-up), floor polish and waxes, window cleaners, degreasers, or paper packages for oily foodstuffs (pizza and pop-corn boxes). ${ }^{133}$ PFCs are a complex group of organic compounds characterized by a carbon chain in which all hydrogen atoms have been replaced by fluorine atoms. This characteristic makes PFCs very persistent in the environment and nondegradable. The PFC perfluorooctane sulfonic acid (PFOS) was classified as a persistent organic pollutant in the Stockholm convention and as a priority hazardous substance in the EU due to its very high persistence in the environment, its bioaccumulation potential and its toxicity. Its use is now restricted in many countries and its production, as well as its concentration in wastewater, have decreased drastically in recent years. ${ }^{134}$ The PFC perfluorooctanoic acid (PFOA) has also recently received more attention due to its toxic and eco-toxic properties and its high persistence. ${ }^{135}$ PFOA and PFOS are among the most abundant PFCs observed in raw municipal wastewaters, with average concentrations around 5-50 ng L ${ }^{-1}$. The sum of the concentrations of the most common PFCs is usually reported in the range of 30-150 ng L ${ }^{-1}$. PFCs are usually not significantly removed $(<5 \%)$ in WWTPs (despite variable removal efficiencies). ${ }^{67,136-138}$ Concentrations in WWTP effluents are thus relatively similar those in the influents (12-13 ng L ${ }^{-1}$ for PFOA and PFOS, Table 1). Despite these very low effluent concentrations, PFOS is still present at a level 20 times higher than its European EQS for surface waters $\left(0.65 \mathrm{ng} \mathrm{L}^{-1}\right)^{126}$ and may persist for a very long time in the environment.

\section{Biocides, Pesticides, and Persistent Organic Pollutants (POPs)}

Biocides and pesticides are designed to destroy or control the growth of targeted organisms, such as plants (herbicides), algae (algicides), insects (insecticides), or fungi (fungicides). More than 500 biocideand pesticide-active ingredients are approved for use in Europe. ${ }^{139,140}$ The term pesticide is commonly used for chemicals applied to protect plants (mainly for agricultural use), whereas the term biocide is 
usually applied for all other purposes (mainly urban use). Biocides are for instance applied in bituminous roof sealing membranes to avoid root penetration, in external facade paintings to avoid algae and moss development, in grass or plant-management (golf, parks, cemeteries), or weed control (roadways, railroads). During rain events, biocides and pesticides can leach from buildings, parks, and gardens, and are partly drained to the combined sewer network. ${ }^{141,142}$ Pesticides in surface waters were often considered to be of agricultural origin, but new studies showed that urban contributions to the river pesticide loads can be in the same range as from agriculture in mixed land use watersheds (urban and agricultural use such as the Swiss Plateau). ${ }^{143}$

Concentrations of pesticides/biocides in municipal wastewater are highly variable as their inputs are influenced by rain events (higher load during rain) and the season (application periods). Constant inputs of several compounds are also observed during dry weather, suggesting household uses. ${ }^{143}$ Apart from concentration peaks reaching several $\mu \mathrm{g} \mathrm{L}^{-1}$ during special events (e.g., disposal activities), average pesticide/biocide concentrations in raw wastewater are usually lower than $1 \mu \mathrm{g} \mathrm{L}^{-1}$, and for most compounds lower than $100 \mathrm{ng} \mathrm{L}^{-1} \cdot{ }^{68,78,144}$ Removal of pesticides/biocides in WWTPs is highly variable, but on average poor efficiencies $(<50 \%)$ are reported (Table 1). ${ }^{78,144}$ Their concentrations in WWTP effluents are thus similar to those in influents, ranging on average for most compounds between 5 and $300 \mathrm{ng}$ $\mathrm{L}^{-1}$ (Table 1). A few exceptions were observed for glyphosate, a widely used herbicide (active substance of the Roundup), its degradation product AMPA, and the herbicide mecoprop (average concentrations often observed above $500 \mathrm{ng} \mathrm{L}{ }^{-1}$ ). Despite their low concentrations, some pesticides such as diazinon, diuron, and irgarol are still at concentrations higher than their proposed EQS values (Table 1), leading to potential risks for sensitive aquatic organisms in case of low dilution of the effluents.

Several pesticides from the 'old' generation (more hydrophobic, with $\log K_{\text {OW }}$ from 3.6 to 6.2 ) were classified as persistent organic pollutants (POPs) (cf. Table 1) in the Stockholm convention due to their persistence in the environment, their accumulation in living organisms and their toxicity to human and wildlife. The use of these pesticides is now banned or strongly limited in many countries since the convention entered into force on May 2004. Concentrations of these pesticides in raw municipal wastewater in 2001-2003 in Greece were on average between 10

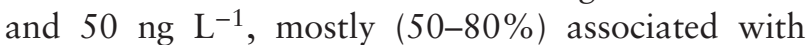
particles. ${ }^{145}$ All these compounds were well removed
(75-91\%, mostly by sorption) during treatment, resulting in concentrations between 1 and $14 \mathrm{ng} \mathrm{L}^{-1}$ in the effluent. ${ }^{70}$ This is lower than their respective EQS (5-25 ng $\left.\mathrm{L}^{-1}\right)$, except for the sum of aldrin, dieldrin, and endrin, which is close to their EQS, and for heptachlor which exceeds more than 50,000 times its EQS (0.0002 ng L ${ }^{-1}$ ) (Table 1).

Other nonpesticide POPs, such as the toxic polychlorinated biphenyls (PCBs), used over many years as heat exchange fluids in electric transformers or as additives in paint and oil, are still found in municipal wastewaters despite their ban in many countries since $1970-1990 .{ }^{71}$ A total of 209 PCB congeners exist, where 1-10 chlorine atoms are attached in different configurations to the two benzene rings. Concentrations of PCBs in raw municipal wastewaters are reported in the low $n g \mathrm{~L}^{-1}$ range, with the sum of the 209 congeners estimated on average around 50-100 ng $\mathrm{L}^{-1} \cdot{ }^{69,71}$ An average removal of $75 \%$ of the sum of PCBs in conventional WWTPs was typically reported. ${ }^{69,70}$ Because of their hydrophobicity and low biodegradability, PCBs are mostly removed by sorption. ${ }^{69,70}$ PCBs in WWTP effluents are usually found at concentrations lower than $1 \mathrm{ng}$ $\mathrm{L}^{-1}$ for individual congeners, with the sum of the 209 congeners at around $20 \mathrm{ng} \mathrm{L}^{-1}$, which is higher than their PNEC (1 $\mathrm{ng} \mathrm{L}^{-1}$, Table 1). ${ }^{63,71}$ PCBs released in surface waters can accumulate in fish, rendering them unfit for human consumption. ${ }^{146}$ Sources of PCBs to the aquatic environment are, however, diverse and the highest inputs are often coming from contaminated sites, stormwaters, and combined sewer overflows (CSOs) (due to atmospheric deposition). ${ }^{147}$ Inputs from WWTP effluents are usually low but may contaminate sediments in the vicinity of the plant. ${ }^{148}$

\section{Heavy Metals}

Heavy metals are elements that are not biodegradable, tend to accumulate in living organisms and are known to be toxic if present in excessive levels. Some of these elements, such as zinc or copper, are essential for life in trace concentrations but accumulation in the organism can lead to serious diseases. ${ }^{149}$ The term 'heavy metal' refers generally to (post-) transition metals with a density greater than $5 \mathrm{~kg} \mathrm{~L}^{-1},{ }^{149}$ but some other metals or metalloids are also sometime included in this category, such as aluminum or arsenic. Toxic heavy metals of particular concern in wastewater include zinc $(\mathrm{Zn})$, copper $(\mathrm{Cu})$, nickel $(\mathrm{Ni})$, mercury $(\mathrm{Hg})$, cadmium $(\mathrm{Cd})$, lead $(\mathrm{Pb})$, and chromium $(\mathrm{Cr}) .{ }^{149}$

Historically, heavy metals in wastewater have been strongly associated with industrial emissions. In recent years, probably due to more stringent 
regulations and displacement of industrial activities out of cities, industries are no longer considered to be the main source of heavy metals in municipal wastewater. ${ }^{73}$ Household sewage is reported to be an important source of heavy metals such as $\mathrm{Cu}$ (corrosion of pipes and taps, food), $\mathrm{Zn}$ (leaching from galvanized material, food) and $\mathrm{Hg}$ (amalgam), and contribute also to the load of $\mathrm{Pb}$ (leaching from old lead plumbing), $\mathrm{Cr}$ and $\mathrm{Ni}$ (stainless steel products) or Cd (artist paint pigments). Stormwater runoff can also be a significant source of heavy metals, especially from building materials, such as $\mathrm{Zn}$ (from galvanized metal) or $\mathrm{Cu}$ (roofs, catenaries of trains/trolleybuses), but also from traffic ( $\mathrm{Zn}$ from tires, $\mathrm{Cu}$, and $\mathrm{Pb}$ from brake linings or asphalt) or agricultural runoff $(\mathrm{Cu}$ used as a fungicide). Business and industry sewage can also contribute significantly to the total load of heavy metals. ${ }^{150,151}$

Concentrations of heavy metals in municipal wastewater are highly variable as metals come from very diverse sources. In raw wastewater, metal concentrations are in the range of $\mu \mathrm{g} \mathrm{L}^{-1}$ to $\mathrm{mg} \mathrm{L}^{-1}$, except for $\mathrm{Cd}$ and $\mathrm{Hg}$ (ng L ${ }^{-1}$ to $\mu \mathrm{g} \mathrm{L}^{-1}$ ), with abundances usually observed as follows (median total/dissolved concentrations in $\mu \mathrm{g} \mathrm{L}^{-1}$ in 16 WWTPs in the UK) ${ }^{43,152}$ : Al $(1470 / 40)>\mathrm{Fe}(1097 / 215)>\mathrm{Zn}(160 / 37)>\mathrm{Cu}$ $(65 / 17)>\mathrm{Cr}(12 /-)=\mathrm{Pb}(12 / 2)=\mathrm{Ni}(11 / 6.3)>\mathrm{Cd}$ $(0.45 / 0.1)>\mathrm{Hg}(0.053 / 0.014)$. High concentrations of $\mathrm{Al}$ and Fe may be due to addition of these chemicals as coagulant to treat water or as constituents of several natural clay minerals. Heavy metals are mostly associated with suspended solids $(>75 \%$ of the total concentration), except for $\mathrm{Ni}(>50 \%$ in the dissolved phase). Therefore, removal of heavy metals in WWTPs is strongly associated with the removal of suspended solids (TSS), as illustrated in Figure 5. As presented in Table 1 , high metal removal efficiency $(>75 \%)$ can be achieved in most WWTPs due to important removal of TSS $(>90 \%)$, except for $\mathrm{Ni}$, with median removal around $30 \%$. Poor nickel removal (or even enrichment in the process) may also be caused, to some extent, by impurities (about $40 \mathrm{ppm}$ of $\mathrm{Ni}, \mathrm{Cu}$, and $\mathrm{Cr}$ ) in the chemicals (e.g., iron chloride) added during the treatment for phosphate removal. ${ }^{153}$ Volatilization is not expected to be a significant removal mechanism, except for mercury $(2-10 \%) .{ }^{154,155}$ Despite good elimination of metals associated with particles, conventional treatments have, however, little effect (usually less than $60 \%$ ) on the dissolved concentration. Thus, in WWTP effluents, most of the metals (except for Al and $\mathrm{Fe}$ ) are found predominantly $(50-90 \%)$ in the dissolved phase. Concentrations in effluents are usually in the low $\mu \mathrm{g} \mathrm{L}^{-1}$ range, $\mathrm{Zn}$ being the most abundant toxic heavy metal, followed by $\mathrm{Cu}$ and $\mathrm{Ni}$ (Table 1 ). In some effluents, these concentrations can slightly exceed the proposed EQS for surface waters, especially for $\mathrm{Zn}, \mathrm{Cu}$, and $\mathrm{Ni}$ (Table 1), leading to a risk for aquatic organisms in the case of low dilution in the receiving waters. High sediment contaminations with heavy metals in the proximity of WWTP outfalls in lakes were reported, representing a significant source of toxicity for benthic organisms. ${ }^{148}$

\section{Polycyclic Aromatic Hydrocarbons (PAHs)}

Polycyclic aromatic hydrocarbons are a family of over 100 organic compounds comprised of two or more fused benzene rings without any heteroatoms. They come primarily from incomplete combustion or pyrolysis of organic material such as oil, petroleum, coal, and wood, both from natural and anthropogenic sources, the latter being the most dominant. ${ }^{156}$ Most PAHs do not have commercial uses, apart for naphthalene used in products such as lubricants, bathroom products, deodorant discs, wood preservatives, fungicides, or concrete plasticizers. ${ }^{72}$ They are usually released into the atmosphere via gaseous emissions and are then subject to wet and dry deposition. They are widely spread throughout the environment, causing water, soil, and air pollution. Some of them are highly carcinogenic, mutagenic, and teratogenic, and relatively persistent. Eight PAHs
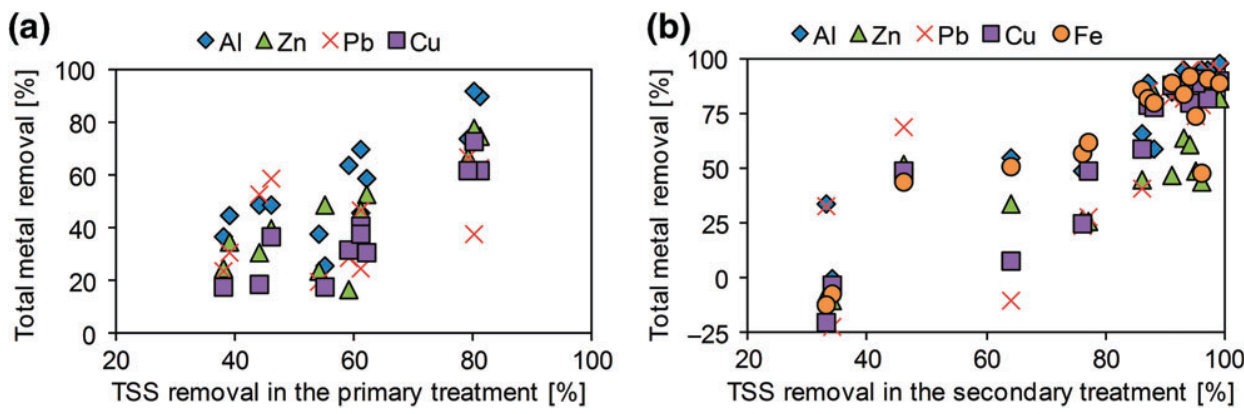

FIGURE 5 | Removal of heavy metals (total concentration) as a function of the removal of suspended solids in (a) primary treatments and (b) secondary treatments. Results of an extensive study made on 16 WWTPs in the UK during 2010/2011. (Data adapted with permission from Ref 43) 
have been identified as priority pollutants in water in Europe. ${ }^{126}$ Due to their hydrophobicity, low water solubility, and variable volatility (which decreases with the number of condensed benzene rings), they have tendency to bind to particles and accumulate in organisms. PAHs are not specific domestic wastewater pollutants but, because of their wide presence in urban environment, are especially adsorbed onto particles on roads. They can thus reach municipal sewers during rain events (urban runoff). PAHs concentrations in raw wastewater are, however, relatively low, with median concentrations in UK and Italian wastewater around $20 \mathrm{ng} \mathrm{L}^{-1}$ for heavy PAHs such as benzo(a)pyrene, benzo(b)fluoranthene, benzo(k)fluoranthene, benzo(g,h,i)perylene and indeno(1,2,3.cd)pyrene, and slightly higher for lighter PAHs such as anthracene $\left(50 \mathrm{ng} \mathrm{L}^{-1}\right)$, fluoranthene (110 ng L $\mathrm{L}^{-1}$ ) and naphthalene (1100 ng L $\left.{ }^{-1}\right) .{ }^{43,72}$ The sum of the concentrations of the 16 PAHs (recommended by the US-EPA) in Italian wastewater was between 0.2 and $1.5 \mu \mathrm{g} \mathrm{L}^{-1} .{ }^{72}$

PAH removal in different WWTPs is highly variable, but the median removal, mainly by sorption, is between $60 \%$ to more than $90 \%$, depending on the compound (Table 1). High molecular weight PAHs, which are also the most toxic, are usually over $80 \%$ removed. ${ }^{43,72}$ The sum of the 16 US-EPA PAHs is reported to be reduced over $70 \%$ in most WWTPs. ${ }^{72,157}$

Effluent concentrations of UK and Italian WWTPs were around 1-3 ng $\mathrm{L}^{-1}$ for heavy PAHs and between 10 to $50 \mathrm{ng} \mathrm{L}^{-1}$ for lighter compounds (Table 1). Despite these very low concentrations, several PAHs are still above their EQS for surface waters (Table 1). Thus, PAHs may pose a risk to the environment in case of low dilution $(<10$ times) of the effluent. Sediment contaminations with PAHs in the proximity of WWTP outfalls in lakes were also reported. ${ }^{148}$

\section{Volatile Organic Compounds (VOCs)}

Volatile organic compounds have a high vapor pressure at ambient temperature, resulting to a low boiling point (usually between less than $50^{\circ} \mathrm{C}$ to $250^{\circ} \mathrm{C}$ at $1 \mathrm{~atm})$. They are extensively used in fuels, paints, aerosols, cosmetics, solvents, disinfectants, and pesticides, and are often present in significant concentrations in municipal wastewater. Aromatic VOCs, such as benzene, toluene, ethylbenzene, xylene, and styrene (BTEXS group), are especially of concern due to their toxicity. In a survey made in Italy, ${ }^{72}$ toluene was the most abundant aromatic VOC in raw municipal wastewater, with 3 to $5 \mu \mathrm{g} \mathrm{L}^{-1}$. Xylene, styrene, and ethylbenzene were found at slightly lower concentrations (100-300 $\mathrm{ng} \mathrm{L}^{-1}$ ) and benzene usually below $60 \mathrm{ng} \mathrm{\textrm {L } ^ { - 1 }}$. The removal of these aromatic VOCs is usually high $(>70 \%)$ during conventional treatment (Table 1). Volatilization (surface volatilization in primary treatment and stripping during aeration) is likely to be the major removal mechanism, ${ }^{158}$ but biodegradation can also play an important role. ${ }^{159,160}$ As the off-gas is usually not treated in municipal WWTPs, transfer of VOCs to the atmosphere can contribute to air pollution around WWTPs. ${ }^{159}$ The concentrations found in the effluent are not expected to cause aquatic toxicity (Table 1 ).

\section{Synthesis and Risk Evaluation}

The average removal efficiencies in conventional WWTPs and the average effluent concentrations of 168 micropollutants presented in this review are synthesized in Figure 6. The sum of the concentrations of these 168 micropollutants in WWTP effluents is on average around $0.75 \mathrm{mg} \mathrm{L}^{-1}$, with $0.46 \mathrm{mg} \mathrm{L}^{-1}$ only for organic pollutants. Half of the load of organic pollutants is dominated by surfactants, one third by a few household chemicals (two sweeteners, two corrosion inhibitors, and two chelating agents), and $13 \%$ by pharmaceuticals. The highest effluent concentrations (>10 $\mu \mathrm{g} \mathrm{L}^{-1}$ ) were observed for several heavy metals (Al, Fe, Zn), surfactants (soap, LAS), some household chemicals (chelating agents EDTA and NTA, sweeteners acesulfame and sucralose), and some pharmaceuticals (iomeprol, iohexol, metformin).

Hydrophobic pollutants (heavy metals, PAHs, POPs, several household chemicals like brominated flame retardants, several personal care products), and easily biodegradable pollutants (surfactants, plastic additives, hormones, several PCPs, some pharmaceuticals and household chemicals) are in general largely removed $(>70 \%)$ during treatment. Their effluent concentrations can, however, still be higher than their respective EQS or PNEC values for surface waters. Despite their possible degradation in the environment, risks for sensitive aquatic organisms cannot be excluded in the vicinity of WWTP outfalls due to the constant input of these chemicals (pseudo-persistence).

More hydrophilic (polar) and hardly biodegradable pollutants, e.g., most pharmaceuticals and pesticides/biocides as well as several household chemicals (sweeteners, EDTA, corrosion inhibitors, some phosphorus flame retardants and PFCs), are only poorly removed $(<50 \%)$ during treatment. These compounds thus present a greater risk of contamination of receiving waters and persistence within them. 
(a)

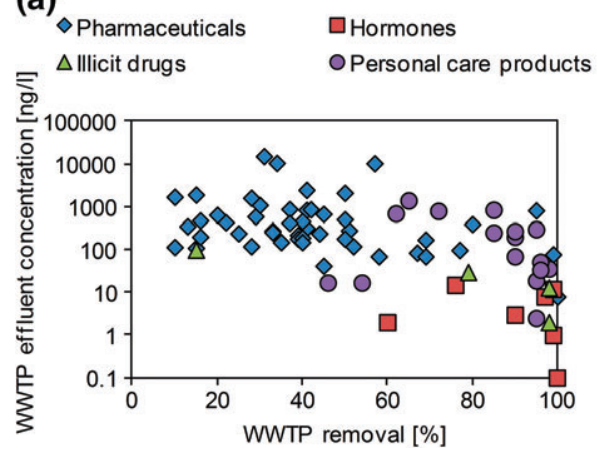

(b)

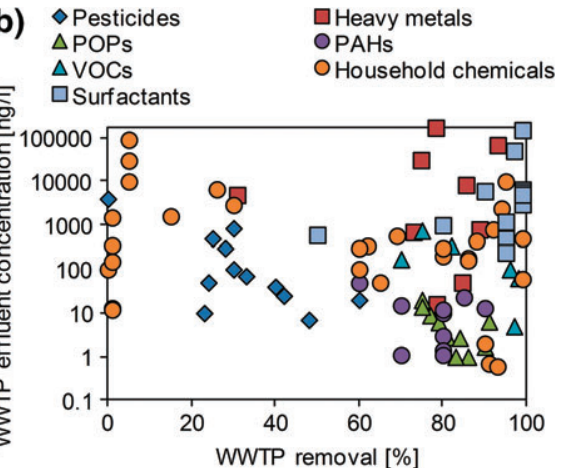

FIGURE 6 | Synthesis of average WWTP removal efficiencies and effluent concentrations of (a) 48 pharmaceuticals (Swiss data), 16 personal care products (5 fragrances, 2 preservatives, 3 antimicrobial agents, 1 insect repellent, 5 UV filters), 7 hormones, and 4 illicit drugs; and (b) 12 pesticides/biocides, 9 heavy metals, 10 persistent organic pollutants (POPs, mainly hydrophobic pesticides and PCBs), 12 polycyclic aromatic hydrocarbons (PAHs), 6 volatile aromatic organic compounds (VOCs), 32 household chemicals (4 sweeteners, 6 plastic additives, 6 corrosion inhibitors, 2 chelating agents, 12 flame retardants, and 2 perfluorinated compounds) and 12 surfactants. Average values from European and American WWTPs, with primary and secondary treatments (equivalent to activated sludge with partial nitrification). Sources of the data are given in Table 1.

The impact of these micropollutants on aquatic organisms in receiving waters is difficult to evaluate due to the diversity of pollutant and modes of action (mixture effect). The risk of a specific compound (without considering the mixture effect) depends on (1) its aquatic toxicity, usually assessed by quality criteria such as the PNECs or EQSs, and (2) its concentration in the surface water, which depends on the effluent concentration, the dilution factor and the stability (persistence) of the compound in the environment.

Concentrations of several micropollutants (55 out of 168) in WWTP effluents are higher than their respective proposed EQS or PNEC for surface waters (Table 1). This is for instance the case for most surfactants (8), several pharmaceuticals (13) and hormones (3), some PCPs (4), PBDEs (2), PFOS, EDTA, plastic additives (3), some pesticides/biocides (6), POPs (4), several heavy metals (5) and PAHs (5). Individual risks can thus not be excluded for these compounds in case of low dilution of the effluents in the receiving waters.

Prioritization of micropollutants released from WWTPs should be assessed based on their load $L$ in the receiving media (contamination of drinking resources), their potential ecotoxicological impacts $T$ (ratio concentration/PNEC) and their persistence in the environment $P$ (which is related to its persistence in WWTPs). On the basis of these three parameters, a basic prioritization is proposed in Table 1 . All classes of micropollutants studied (except VOCs) present an issue regarding their load, their ecotoxicological impacts or their potential persistency in the aquatic environment. This shows that improvement of their removal in WWTPs is necessary.

\section{ENHANCED TREATMENT OF MICROPOLLUTANTS IN WWTPS}

Apart from source control, first strategy that should be applied to avoid the release of micropollutants in wastewater, such as regulations (ban or restriction of harmful compounds), substitution of harmful chemicals by more environmentally friendly substances, or users awareness and promotion of best management practices (via information campaigns or incentive taxes), two other main options exist to reduce the concentration of micropollutants in WWTP effluents: (1) improvement and optimization of the existing treatment technologies and (2) addition of complementary advanced treatments.

\section{Optimization of Conventional Treatments}

As described in the previous section, several micropollutants are at best only partially removed in conventional WWTPs. The presence of pollutants in WWTP effluents can be due to high persistence of the molecule (hydrophilic and not biodegradable compounds), but also to too short contact times (HRTs) with microorganisms to lead to complete biodegradation, not enough diverse bacterial community to metabolize/cometabolize the substance, or poor separation of suspended solids (sorbed fraction). Optimization of conventional treatments to achieve good removal of total suspended solids (TSS), biochemical oxygen demand (BOD), chemical oxygen demand (COD), dissolved and total organic carbon (DOC, TOC), and ammonium $\left(\mathrm{NH}_{4}{ }^{+}\right)$may thus improve the removal of less persistent micropollutants that are poorly removed due to the reasons mentioned above. For instance, achieving low concentration of 

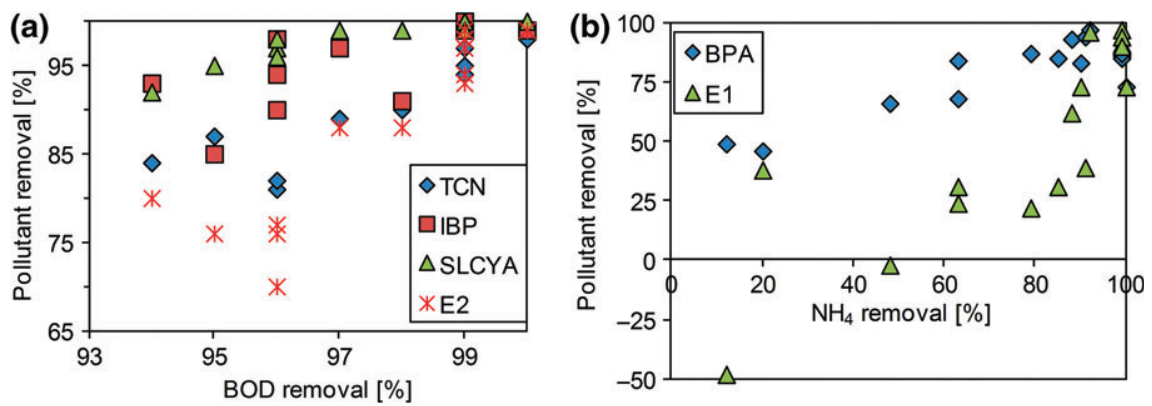

FIG URE 7 | Removal of (a) triclosan (TCN), ibuprofen (IBP), salicylic acid (SLCYA), and 17 $\beta$-estradiol (E2) as a function of BOD removal in conventional WWTPs, and removal of (b) bisphenol A (BPA) and estrone (E1) as a function of ammonium removal in secondary biological treatments. Results of an extensive study made on 16 WWTPs in UK during 1 year in 2010/2011. (Data adapted with permission from Ref 43)

TSS in the effluent, e.g., by sand filtration or advanced decantation, will significantly reduce concentrations of micropollutants associated with solids such as heavy metals, PAHs, PCBs, hydrophobic pesticides, flame retardants (PBDEs), phthalates (DEHP), UV filters, triclosan, or polycyclic musks. Good removal of BOD and ammonium (complete nitrification) may significantly improve the removal of biodegradable pollutants such as ibuprofen, estrogen (E2), salicylic acid, triclosan, bisphenol A, and estrogens (E1) (Figure 7), as well as many other compounds (e.g., atenolol, bezafibrate, norfloxacin, ofloxacin, metronidazole, methylbenzotriazole, simvastatin, gemfibrozil, naproxen, ketoprofen, mefenamic acid, or iomeprol). ${ }^{32,43}$ Therefore, WWTPs that can achieve high removal of TSS, BOD, DOC, and ammonium will certainly perform better in removing several (adsorbable or moderately biodegradable) micropollutants.

\section{Advanced Treatments}

Significant removal improvement of hardly biodegradable and hydrophilic (low sorption affinity) micropollutants such as several pharmaceuticals, pesticides, phosphorus flame retardants, sweeteners, or corrosion inhibitors, seems not to be feasible by optimization of existing conventional treatments. It appears that, for these substances, complementary treatments, called advanced treatments, are necessary. Up to now, mainly physicochemical advanced processes are available, removing pollutants from water either physically by adsorption (e.g., on activated carbon) or tight membrane filtration (nanofiltration, reverse osmosis), or chemically (mainly by oxidation with ozone, $\mathrm{OH}$ radicals, ferrate, $\mathrm{UV} / \mathrm{H}_{2} \mathrm{O}_{2}$, etc.). Currently, two main technologies with a potential for large-scale application in terms of efficiency, cost and energy requirements have been identified: (1) oxidation of micropollutants with ozone and (2) adsorption onto activated carbon. ${ }^{161}$ These two technologies have been tested at large pilot-scale over more than one year in various municipal WWTPs, showing good efficiency in removing a wide range of micropollutants. ${ }^{32,162}$ These two advanced treatments seem thus adapted to reduce the load of micropollutants into the aquatic environment coming from large WWTPs.

\section{CONCLUSION}

A wide range of chemicals ends up into municipal wastewater. The fate of these micropollutants in WWTPs depends on their physicochemical characteristics, in particular their hydrophobicity and sludge sorption affinity, their biodegradability, and their volatility.

Relatively hydrophobic pollutants such as heavy metals, PAHs, POPs, several household chemicals like brominated flame retardants and several personal care products, are usually well removed $(>70 \%)$, mostly by sorption onto sewage sludge. Easily biodegradable pollutants such as surfactants, plastic additives, hormones, several PCPs, some pharmaceuticals and household chemicals, are also well removed by biodegradation/transformation. Some VOCs seem to be significantly removed from the water by volatilization. Despite good removal of these substances, effluent concentrations of some of them (surfactant, heavy metals) can still be relatively high due to their high concentrations in raw wastewater. Good removal efficiencies do, however, not mean that the effluent concentrations will not potentially affect aquatic life, as some of these compounds are toxic at very low concentrations (hormones, POPs, PAHs).

More hydrophilic and poorly-to-moderately biodegradable pollutants are not well removed during conventional treatments. The removal efficiency of some compounds can be improved with modern biological treatments, which are able to achieve 
high removal of BOD and ammonium (nitrification). Many of these polar and hardly biodegradable substances, e.g., most pharmaceuticals, pesticides, and several household chemicals (corrosion inhibitors, sweeteners, EDTA, phosphorus flame retardants, PFCs), are, however, not significantly removed even in modern biological treatments. To decrease their discharge into surface waters, advanced treatments such as ozonation and adsorption onto activated carbon are necessary. This issue was recently considered by the Swiss government, which decided to implement, over the next 20 years, technical measures for micropollutant reduction in WWTPs. ${ }^{163}$
Finally, the potential impacts of the studied compounds were evaluated on single substances. The potential impact of the mixture of all compounds together may generate an important risk for the environment. ${ }^{164} \mathrm{~A}$ better management of micropollutants, from source control (regulation and substitution), user information (proper disposal, moderate and optimal usage, choice of chemicals with lower environmental impacts, etc.) to technical solutions in WWTPs is therefore of highest importance for the preservation of natural resources.

\section{REFERENCES}

1. Schwarzenbach RP, Escher BI, Fenner K, Hofstetter TB, Johnson CA, Von Gunten U, Wehrli B. The challenge of micropollutants in aquatic systems. Science 2006, 313:1072-1077.

2. Alan MV, Barber LB, Gray JL, Lopez EM, Woodling JD, Norris DO. Reproductive disruption in fish downstream from an estrogenic wastewater effluent. Environ Sci Technol 2008, 42:3407-3414.

3. Jobling S, Nolan M, Tyler CR, Brighty G, Sumpter JP. Widespread sexual disruption in wild fish. Environ Sci Technol 1998, 32:2498-2506.

4. Jobling S, Williams R, Johnson A, Taylor A, GrossSorokin M, Nolan M, Tyler CR, van Aerle R, Santos E, Brighty G. Predicted exposures to steroid estrogens in U.K. rivers correlate with widespread sexual disruption in wild fish populations. Environ Health Perspect 2006, 114:32-39.

5. Tyler CR, Jobling S. Roach, sex, and gender-bending chemicals: the feminization of wild fish in English rivers. Bioscience 2008, 58:1051-1059.

6. Gagné F, Bouchard B, André C, Farcy E, Fournier M. Evidence of feminization in wild Elliptio complanata mussels in the receiving waters downstream of a municipal effluent outfall. Comp Biochem Physiol C Toxicol Pharmacol 2011, 153:99-106.

7. Tetreault GR, Bennett CJ, Carl C, Servos MR, McMaster ME. Reproductive and histopathological effects in wild fish inhabiting an effluent-dominated stream, Wascana Creek, SK, Canada. Aquat Toxicol 2012, 110-110:149-161.

8. Tetreault GR, Bennett CJ, Shires K, Knight B, Servos MR, McMaster ME. Intersex and reproductive impairment of wild fish exposed to multiple municipal wastewater discharges. Aquat Toxicol 2011, 104:278-290.

9. Vethaak AD, Lahr J, Schrap SM, Belfroid AC, Rijs GBJ, Gerritsen A, de Boer J, Bulder AS, Grinwis GCM, Kuiper RV, et al. An integrated assessment of estrogenic contamination and biological effects in the aquatic environment of The Netherlands. Chemosphere 2005, 59:511-524.

10. Gagné F, André C, Cejka P, Hausler R, Fournier M. Evidence of neuroendocrine disruption in freshwater mussels exposed to municipal wastewaters. Sci Total Environ 2011, 409:3711-3718.

11. Gillis PL, Gagné F, McInnis R, Hooey TM, Choy ES, André C, Hoque ME, Metcalfe CD. The impact of municipal wastewater effluent on field-deployed freshwater mussels in the Grand River (Ontario, Canada). Environ Toxicol Chem 2014, 33:134-143.

12. Galus M, Jeyaranjaan J, Smith E, Li H, Metcalfe C, Wilson JY. Chronic effects of exposure to a pharmaceutical mixture and municipal wastewater in zebrafish. Aquat Toxicol 2013, 132-133: 212-222.

13. Peschke K, Geburzi J, Kö̈hler HR, Wurm K, Triebskorn R. Invertebrates as indicators for chemical stress in sewage-influenced stream systems: toxic and endocrine effects in gammarids and reactions at the community level in two tributaries of Lake Constance, Schussen and Argen. Ecotoxicol Environ Saf 2014, 106:115-125.

14. Englert D, Zubrod JP, Schulz R, Bundschuh M. Effects of municipal wastewater on aquatic ecosystem structure and function in the receiving stream. Sci Total Environ 2013, 454-455:401-410.

15. Bundschuh M, Pierstorf R, Schreiber WH, Schulz R. Positive effects of wastewater ozonation displayed by in situ bioassays in the receiving stream. Environ $\mathrm{Sci}$ Technol 2011, 45:3774-3780.

16. Berna JL, Cassant G, Hager CD, Rehman N, López I, Schowanek D, Steber J, Taeger K, Wind T. Anaerobic biodegradation of surfactants: scientific review. Tenside Surfact Det 2007, 44:312-347.

17. Scott MJ, Jones MN. The biodegradation of surfactants in the environment. Biochim Biophys Acta Biomembr 2000, 1508:235-251. 
18. Matthijs E, Holt MS, Kiewiet A, Rijs GBJ. Environmental monitoring for linear alkylbenzene sulfonate, alcohol ethoxylate, alcohol ethoxy sulfate, alcohol sulfate, and soap. Environ Toxicol Chem 1999, 18:2634-2644.

19. Feijtel T, Vits H, Murray-Smith R, van Wijk R, Koch V, Schröder R, Birch R, Ten Berge W. Fate of LAS in activated sludge wastewater treatment plants: a model verification study. Chemosphere 1996, 32:1413-1426.

20. Mungray AK, Kumar P. Fate of linear alkylbenzene sulfonates in the environment: a review. Int Biodeter Biodegr 2009, 63:981-987.

21. Schowanek D, David H, Francaviglia R, Hall J, Kirchmann H, Krogh PH, Schraepen N, Smith S, Wildemann T. Probabilistic risk assessment for linear alkylbenzene sulfonate (LAS) in sewage sludge used on agricultural soil. Regul Toxicol Pharmacol 2007, 49:245-259.

22. Field JA, Field TM, Poiger T, Siegrist H, Giger W. Fate of secondary alkane sulfonate surfactants during municipal wastewater treatment. Water Res 1995, 29:1301-1307.

23. McAvoy DC, Dyer SD, Fendinger NJ, Eckhoff WS, Lawrence DL, Begley WM. Removal of alcohol ethoxylates, alkyl ethoxylate sulfates, and linear alkylbenzene sulfonates in wastewater treatment. Environ Toxicol Chem 1998, 17:1705-1711.

24. McAvoy DC, Eckhoff WS, Begley WM, Pessler DG. A comparison of alcohol ethoxylate environmental monitoring data using different analytical procedures. Environ Toxicol Chem 2006, 25:1268-1274.

25. Belanger SE, Dorn PB, Toy R, Boeije G, Marshall SJ, Wind T, Van Compernolle R, Zeller D. Aquatic risk assessment of alcohol ethoxylates in North America and Europe. Ecotoxicol Environ Saf 2006, 64:85-99.

26. Loyo-Rosales JE, Rice CP, Torrents A. Fate of octyland nonylphenol ethoxylates and some carboxylated derivatives in three American wastewater treatment plants. Environ Sci Technol 2007, 41:6815-6821.

27. Ying G-G, Williams B, Kookana R. Environmental fate of alkylphenols and alkylphenol ethoxylates-a review. Environ Int 2002, 28:215-226.

28. Bergé A, Cladière M, Gasperi J, Coursimault A, Tassin B, Moilleron R. Meta-analysis of environmental contamination by alkylphenols. Environ Sci Pollut Res 2012, 19:3798-3819.

29. Guedez AA, Püttmann W. Occurrence and fate of TMDD in wastewater treatment plants in Germany. Water Res 2011, 45:5313-5322.

30. Clara M, Windhofer G, Weilgony P, Gans O, Denner M, Chovanec A, Zessner M. Identification of relevant micropollutants in Austrian municipal wastewater and their behaviour during wastewater treatment. Chemosphere 2012, 87:1265-1272.

31. Kreuzinger N, Fuerhacker M, Scharf S, Uhl M, Gans $\mathrm{O}$, Grillitsch B. Methodological approach towards the environmental significance of uncharacterized substances-quaternary ammonium compounds as an example. Desalination 2007, 215:209-222.

32. Margot J, Kienle C, Magnet A, Weil M, Rossi L, de Alencastro LF, Abegglen C, Thonney D, Chèvre $\mathrm{N}$, Schärer M, et al. Treatment of micropollutants in municipal wastewater: ozone or powdered activated carbon? Sci Total Environ 2013, 461-462:480-498.

33. Oulton RL, Kohn T, Cwiertny DM. Pharmaceuticals and personal care products in effluent matrices: a survey of transformation and removal during wastewater treatment and implications for wastewater management. J Environ Monit 2010, 12:1956-1978.

34. Loos R, Carvalho R, António DC, Comero S, Locoro G, Tavazzi S, Paracchini B, Ghiani M, Lettieri T, Blaha $\mathrm{L}$, et al. EU-wide monitoring survey on emerging polar organic contaminants in wastewater treatment plant effluents. Water Res 2013, 47:6475-6487.

35. Lubliner B, Redding M, Ragsdale D. Pharmaceuticals and personal care products in municipal wastewater and their removal by nutrient treatment technologies. 2010. Available at: https://fortress.wa.gov/ecy/publi cations/publications/1003004.pdf. (Accessed March 21, 2014).

36. DGE. Statement 2012 of the wastewater treatment in canton Vaud, Switzerland [Bilan 2012 de l'épuration vaudoise]. 2013. Available at: http://www. vd.ch/fileadmin/user_upload/themes/environnement/ eau/fichiers_pdf/bilan_2012_epuration_Vaud.pdf. (Accessed October 10, 2014).

37. Verlicchi P, Al Aukidy M, Zambello E. Occurrence of pharmaceutical compounds in urban wastewater: removal, mass load and environmental risk after a secondary treatment-a review. Sci Total Environ 2012, 429:123-155.

38. Kase R, Eggen RIL, Junghans M, Götz C, Hollender J. Assessment of micropollutants from municipal wastewater: combination of exposure and ecotoxicological effect data for Switzerland. In: Einschlag F, ed. Waste Water: Evaluation and Management. Rijeka, Croatia: InTech; 2011, 31-54.

39. Kostich MS, Batt AL, Lazorchak JM. Concentrations of prioritized pharmaceuticals in effluents from 50 large wastewater treatment plants in the US and implications for risk estimation. Environ Pollut 2014, 184:354-359.

40. Gardner M, Comber S, Scrimshaw MD, Cartmell E, Lester J, Ellor B. The significance of hazardous chemicals in wastewater treatment works effluents. Sci Total Environ 2012, 437:363-372.

41. Huerta-Fontela M, Galceran MT, Ventura F. Fast liquid chromatography-quadrupole-linear ion trap mass spectrometry for the analysis of pharmaceuticals and hormones in water resources. J Chromatogr A 2010, 1217:4212-4222.

42. Oosterhuis M, Sacher F, ter Laak TL. Prediction of concentration levels of metformin and other high consumption pharmaceuticals in wastewater and regional 
surface water based on sales data. Sci Total Environ 2013, 442:380-388.

43. Gardner M, Jones V, Comber S, Scrimshaw MD, Coello-Garcia T, Cartmell E, Lester J, Ellor B. Performance of UK wastewater treatment works with respect to trace contaminants. Sci Total Environ 2013, 456-457:359-369.

44. Bijlsma L, Emke E, Hernández F, de Voogt P. Investigation of drugs of abuse and relevant metabolites in Dutch sewage water by liquid chromatography coupled to high resolution mass spectrometry. Chemosphere 2012, 89:1399-1406.

45. Kasprzyk-Hordern B, Dinsdale RM, Guwy AJ. The removal of pharmaceuticals, personal care products, endocrine disruptors and illicit drugs during wastewater treatment and its impact on the quality of receiving waters. Water Res 2009, 43:363-380.

46. Clara M, Gans O, Windhofer G, Krenn U, Hartl W, Braun K, Scharf S, Scheffknecht C. Occurrence of polycyclic musks in wastewater and receiving water bodies and fate during wastewater treatment. Chemosphere 2011, 82:1116-1123.

47. Kupper T, Plagellat C, Brändli RC, de Alencastro LF, Grandjean D, Tarradellas J. Fate and removal of polycyclic musks, UV filters and biocides during wastewater treatment. Water Res 2006, 40:2603-2612.

48. Bester K, Klasmeier J, Kupper T. Emissions of OTNE (Iso-E-super) - mass flows in sewage treatment plants. Chemosphere 2008, 71:2003-2010.

49. Fatta-Kassinos D, Bester K, Kümmerer K, eds. Xenobiotics in the Urban Water Cycle: Mass Flows, Environmental Processes, Mitigation and Treatment Strategies. Environmental Pollution, vol. 16. the Netherlands: Springer; 2010.

50. Yang J-J, Metcalfe CD. Fate of synthetic musks in a domestic wastewater treatment plant and in an agricultural field amended with biosolids. Sci Total Environ 2006, 363:149-165.

51. González-Mariño I, Quintana JB, Rodríguez I, Cela R. Evaluation of the occurrence and biodegradation of parabens and halogenated by-products in wastewater by accurate-mass liquid chromatography-quadrupole-time-of-flight-mass spectrometry (LC-QTOF-MS). Water Res 2011, 45:6770-6780.

52. Lozano N, Rice CP, Ramirez M, Torrents A. Fate of triclocarban, triclosan and methyltriclosan during wastewater and biosolids treatment processes. Water Res 2013, 47:4519-4527.

53. Balmer ME, Buser HR, Müller MD, Poiger T. Occurrence of some organic UV filters in wastewater, in surface waters, and in fish from Swiss lakes. Environ Sci Technol 2005, 39:953-962.

54. Kokotou MG, Thomaidis NS. Determination of eight artificial sweeteners in wastewater by hydrophilic interaction liquid chromatography-tandem mass spectrometry. Anal Methods 2013, 5:3825-3833.

55. Lange FT, Scheurer M, Brauch HJ. Artificial sweeteners: a recently recognized class of emerging environmental contaminants-a review. Anal Bioanal Chem 2012, 403:2503-2518.

56. Bergé A, Cladière M, Gasperi J, Coursimault A, Tassin B, Moilleron R. Meta-analysis of environmental contamination by phthalates. Environ Sci Pollut Res 2013, 20:8057-8076.

57. Reemtsma T, Weiss S, Mueller J, Petrovic M, González S, Barcelo D, Ventura F, Knepper TP. Polar pollutants entry into the water cycle by municipal wastewater: a European perspective. Environ Sci Technol 2006, 40:5451-5458.

58. Alder AC, Siegrist H, Gujer W, Giger W. Behaviour of NTA and EDTA in biological wastewater treatment. Water Res 1990, 24:733-742.

59. Kari FG, Giger W. Speciation and fate of ethylenediaminetetraacetate (EDTA) in municipal wastewater treatment. Water Res 1996, 30:122-134.

60. Knepper TP. Synthetic chelating agents and compounds exhibiting complexing properties in the aquatic environment. Trends Anal Chem 2003, 22:708-724.

61. Nyholm JR, Grabic R, Arp HPH, Moskeland T, Andersson PL. Environmental occurrence of emerging and legacy brominated flame retardants near suspected sources in Norway. Sci Total Environ 2013, 443:307-314.

62. North KD. Tracking polybrominated diphenyl ether releases in a wastewater treatment plant effluent, Palo Alto, California. Environ Sci Technol 2004, 38:4484-4488.

63. Hope BK, Pillsbury L, Boling B. A state-wide survey in Oregon (USA) of trace metals and organic chemicals in municipal effluent. Sci Total Environ 2012, 417-418:263-272.

64. Potvin CM, Long Z, Zhou H. Removal of tetrabromobisphenol A by conventional activated sludge, submerged membrane and membrane aerated biofilm reactors. Chemosphere 2012, 89:1183-1188.

65. Meyer J, Bester K. Organophosphate flame retardants and plasticisers in wastewater treatment plants. J Environ Monit 2004, 6:599-605.

66. Zeng L, Li H, Wang T, Gao Y, Xiao K, Du Y, Wang $\mathrm{Y}$, Jiang G. Behavior, fate, and mass loading of short chain chlorinated paraffins in an advanced municipal sewage treatment plant. Environ Sci Technol 2013, 47:732-740.

67. Guo R, Sim W-J, Lee E-S, Lee J-H, Oh J-E. Evaluation of the fate of perfluoroalkyl compounds in wastewater treatment plants. Water Res 2010, 44:3476-3486.

68. Singer H, Jaus S, Hanke I, Lück A, Hollender J, Alder AC. Determination of biocides and pesticides 
by on-line solid phase extraction coupled with mass spectrometry and their behaviour in wastewater and surface water. Environ Pollut 2010, 158:3054-3064.

69. Blanchard M, Teil MJ, Ollivon D, Legenti L, Chevreuil M. Polycyclic aromatic hydrocarbons and polychlorobiphenyls in wastewaters and sewage sludges from the Paris area (France). Environ Res 2004, 95:184-197.

70. Katsoyiannis A, Samara C. Persistent organic pollutants (POPs) in the sewage treatment plant of Thessaloniki, northern Greece: occurrence and removal. Water Res 2004, 38:2685-2698.

71. Balasubramani A, Howell NL, Rifai HS. Polychlorinated biphenyls (PCBs) in industrial and municipal effluents: concentrations, congener profiles, and partitioning onto particulates and organic carbon. Sci Total Environ 2014, 473-474:702-713.

72. Fatone F, Di Fabio S, Bolzonella D, Cecchi F. Fate of aromatic hydrocarbons in Italian municipal wastewater systems: an overview of wastewater treatment using conventional activated-sludge processes (CASP) and membrane bioreactors (MBRs). Water Res 2011, 45:93-104.

73. Ziolko D, Martin OV, Scrimshaw MD, Lester JN. An evaluation of metal removal during wastewater treatment: the potential to achieve more stringent final effluent standards. Crit Rev Env Sci Technol 2011, 41:733-769.

74. Jelic A, Gros M, Ginebreda A, Cespedes-Sánchez R, Ventura F, Petrovic M, Barcelo D. Occurrence, partition and removal of pharmaceuticals in sewage water and sludge during wastewater treatment. Water Res 2011, 45:1165-1176.

75. McClellan K, Halden RU. Pharmaceuticals and personal care products in archived U.S. biosolids from the 2001 EPA national sewage sludge survey. Water Res 2010, 44:658-668.

76. Yan Q, Gao X, Huang L, Gan XM, Zhang YX, Chen YP, Peng XY, Guo JS. Occurrence and fate of pharmaceutically active compounds in the largest municipal wastewater treatment plant in Southwest China: mass balance analysis and consumption back-calculated model. Chemosphere 2014, 99:160-170.

77. Hörsing M, Ledin A, Grabic R, Fick J, Tysklind M, Jansen JC, Andersen HR. Determination of sorption of seventy-five pharmaceuticals in sewage sludge. Water Res 2011, 45:4470-4482.

78. Campo J, Masiá A, Blasco C, Picó Y. Occurrence and removal efficiency of pesticides in sewage treatment plants of four Mediterranean River Basins. J Hazard Mater 2013, 263:146-157.

79. Margot J. Micropollutant removal from municipal wastewater: from conventional treatments to advanced biological processes. PhD Thesis, No 6505, Ecole Polytechnique Fédérale de Lausanne, 2015.

80. Joss A, Carballa M, Kreuzinger N, Siegrist H, Zabczynski S. Wastewater Treatment. In: Ternes TA,
Joss A, eds. Human Pharmaceuticals, Hormones and Fragrances: The Challenge of Micropollutants in Urban Water Management. London: IWA Publishing; 2006.

81. Pomiès M, Choubert JM, Wisniewski C, Coquery M. Modelling of micropollutant removal in biological wastewater treatments: a review. Sci Total Environ 2013, 443:733-748.

82. Barret M, Carrère H, Latrille E, Wisniewski C, Patureau D. Micropollutant and sludge characterization for modeling sorption equilibria. Environ Sci Technol 2010, 44:1100-1106.

83. Barret M, Patureau D, Latrille E, Carrère H. A three-compartment model for micropollutants sorption in sludge: methodological approach and insights. Water Res 2010, 44:616-624.

84. Katsoyiannis A, Samara C. The fate of Dissolved Organic Carbon (DOC) in the wastewater treatment process and its importance in the removal of wastewater contaminants. Environ Sci Pollut Res 2007, 14:284-292.

85. Tran NH, Urase T, Ngo HH, Hu J, Ong SL. Insight into metabolic and cometabolic activities of autotrophic and heterotrophic microorganisms in the biodegradation of emerging trace organic contaminants. Bioresour Technol 2013, 146:721-731.

86. Benner J, Helbling DE, Kohler H-PE, Wittebol J, Kaiser E, Prasse C, Ternes TA, Albers CN, Aamand $\mathrm{J}$, Horemans B, et al. Is biological treatment a viable alternative for micropollutant removal in drinking water treatment processes? Water Res 2013, 47:5955-5976.

87. Fischer K, Majewsky M. Cometabolic degradation of organic wastewater micropollutants by activated sludge and sludge-inherent microorganisms. Appl Microbiol Biotechnol 2014, 98:6583-6597.

88. Joss A, Zabczynski S, Göbel A, Hoffmann B, Löffler D, McArdell CS, Ternes TA, Thomsen A, Siegrist H. Biological degradation of pharmaceuticals in municipal wastewater treatment: proposing a classification scheme. Water Res 2006, 40:1686-1696.

89. Cirja M, Ivashechkin P, Schäffer A, Corvini PFX. Factors affecting the removal of organic micropollutants from wastewater in conventional treatment plants (CTP) and membrane bioreactors (MBR). Rev Environ Sci Biotechnol 2008, 7:61-78.

90. Ying GG, Zhao JL, Zhou LJ, Liu S. Fate and occurrence of pharmaceuticals in the aquatic environment (surface water and sediment). In: Petrovic M, Perez S, Barcelo D, eds. Comprehensive Analytical Chemistry. Analysis, Removal, Effects and Risk of Pharmaceuticals in the Water Cycle: Occurrence and Transformation in the Environment, vol. 62. Oxford, UK: Elsevier Science; 2013, 453-557.

91. Schwarzenbach RP, Gschwend PM, Imboden DM. Environmental Organic Chemistry. 2nd ed. Hoboken, NJ: John Wiley \& Sons; 2003. 
92. Knepper TP, Berna JL. Surfactants: properties, production, and environmental aspects. In: Knepper TP, Barceló D, de Voogt P, eds. Comprehensive Analytical Chemistry, vol. 40. Amsterdam: Elsevier; 2003, 1-49.

93. Ternes TA, Joss A. Human Pharmaceuticals, Hormones and Fragrances: The Challenge of Micropollutants in Urban Water Management. London: IWA Publishing; 2006.

94. Besse JP, Kausch-Barreto C, Garric J. Exposure assessment of pharmaceuticals and their metabolites in the aquatic environment: application to the French situation and preliminary prioritization. Hum Ecol Risk Assess 2008, 14:665-695.

95. Ortiz de García S, Pinto Pinto G, García Encina P, Irusta Mata R. Consumption and occurrence of pharmaceutical and personal care products in the aquatic environment in Spain. Sci Total Environ 2013, 444:451-465.

96. Ikehata K, Jodeiri Naghashkar N, Gamal E-DM. Degradation of aqueous pharmaceuticals by ozonation and advanced oxidation processes: a review. Ozone Sci Eng 2006, 28:353-414.

97. Lara-Martín PA, González-Mazo E, Petrovic M, Barceló D, Brownawell BJ. Occurrence, distribution and partitioning of nonionic surfactants and pharmaceuticals in the urbanized Long Island Sound Estuary (NY). Mar Pollut Bull 2014, 85:710-719.

98. Kidd KA, Blanchfield PJ, Mills KH, Palace VP, Evans RE, Lazorchak JM, Flick RW. Collapse of a fish population after exposure to a synthetic estrogen. Proc Natl Acad Sci U S A 2007, 104:8897-8901.

99. Gracia-Lor E, Ibáñez M, Zamora T, Sancho JV, Hernández F. Investigation of pharmaceutical metabolites in environmental waters by LC-MS/MS. Environ Sci Pollut Res 2014, 21:5496-5510.

100. Evgenidou EN, Konstantinou IK, Lambropoulou DA. Occurrence and removal of transformation products of PPCPs and illicit drugs in wastewaters: a review. Sci Total Environ 2015, 505:905-926.

101. Been F, Rossi L, Ort C, Rudaz S, Delémont O, Esseiva P. Population normalization with ammonium (NH4-N) in wastewater-based epidemiology: application to illicit drugs monitoring. Environ Sci Technol 2014, 48:8162-8169. doi:10.1021/es5008388.

102. Kubwabo C, Fan X, Rasmussen PE, Wu F. Determination of synthetic musk compounds in indoor house dust by gas chromatography-ion trap mass spectrometry. Anal Bioanal Chem 2012, 404:467-477.

103. Clara M, Strenn B, Gans O, Martinez E, Kreuzinger N, Kroiss H. Removal of selected pharmaceuticals, fragrances and endocrine disrupting compounds in a membrane bioreactor and conventional wastewater treatment plants. Water Res 2005, 39:4797-4807.

104. Horii Y, Reiner JL, Loganathan BG, Senthil Kumar K, Sajwan K, Kannan K. Occurrence and fate of polycyclic musks in wastewater treatment plants in
Kentucky and Georgia, USA. Chemosphere 2007, 68:2011-2020.

105. Upadhyay N, Sun Q, Allen JO, Westerhoff P, Herckes P. Synthetic musk emissions from wastewater aeration basins. Water Res 2011, 45:1071-1078.

106. Weinberg I, Dreyer A, Ebinghaus R. Waste water treatment plants as sources of polyfluorinated compounds, polybrominated diphenyl ethers and musk fragrances to ambient air. Environ Pollut 2011, 159:125-132.

107. Ramirez AJ, Brain RA, Usenko S, Mottaleb MA, O'Donnell JG, Stahl LL, Wathen JB, Snyder BD, Pitt JL, Perez-Hurtado P, et al. Occurrence of pharmaceuticals and personal care products in fish: results of a national pilot study in the United States. Environ Toxicol Chem 2009, 28:2587-2597.

108. Kirchhof MG, de Gannes GC. The health controversies of parabens. Skin Therapy Lett 2013, 18:5-7.

109. Guerra P, Kim M, Shah A, Alaee M, Smyth SA. Occurrence and fate of antibiotic, analgesic/ anti-inflammatory, and antifungal compounds in five wastewater treatment processes. Sci Total Environ 2014, 473-474:235-243.

110. Aronson D, Weeks J, Meylan B, Guiney DP, Howard HP. Environmental release, environmental concentrations, and ecological risk of N,N-diethyl-m-toluamide (DEET). Integr Environ Assess Manag 2012, 8:135-166

111. Stevens-Garmon J, Drewes JE, Khan SJ, McDonald JA, Dickenson ERV. Sorption of emerging trace organic compounds onto wastewater sludge solids. Water Res 2011, 45:3417-3426.

112. Tsui MMP, Leung HW, Lam PKS, Murphy MB. Seasonal occurrence, removal efficiencies and preliminary risk assessment of multiple classes of organic UV filters in wastewater treatment plants. Water Res 2014, 53:58-67.

113. Sang Z, Jiang Y, Tsoi YK, Leung KSY. Evaluating the environmental impact of artificial sweeteners: a study of their distributions, photodegradation and toxicities. Water Res 2014, 52:260-264.

114. Huang PC, Liou SH, Ho IK, Chiang HC, Huang HI, Wang SL. Phthalates exposure and endocrinal effects: an epidemiological review. J Food Drug Anal 2012, 20:719-733.

115. Michałowicz J. Bisphenol A: sources, toxicity and biotransformation. Environ Toxicol Pharmacol 2014, 37:738-758.

116. Liao C, Kannan K. Widespread occurrence of bisphenol A in paper and paper products: implications for human exposure. Environ Sci Technol 2011, 45:9372-9379.

117. de Kermoysan G, Joachim S, Baudoin P, Lonjaret M, Tebby C, Lesaulnier F, Lestremau F, Chatellier C, Akrour Z, Pheron E, et al. Effects of bisphenol A on different trophic levels in a lotic experimental ecosystem. Aquat Toxicol 2013, 144-145:186-198. 
118. Vetter W, Lorenz J. Determination of benzotriazoles in dishwasher tabs from Germany and estimation of the discharge into German waters. Environ Sci Pollut Res 2013, 20:4435-4440.

119. Ecotox Center. Quality standards for organic trace substances in surface water. 2014. Available at: http:// www.oekotoxzentrum.ch/expertenservice/qualitaets kriterien/vorschlaege/index_EN. (Accessed March 16, 2014).

120. Kloepfer A, Jekel M, Reemtsma T. Occurrence, sources, and fate of benzothiazoles in municipal wastewater treatment plants. Environ Sci Technol 2005, 39:3792-3798.

121. Stasinakis AS, Thomaidis NS, Arvaniti OS, Asimakopoulos AG, Samaras VG, Ajibola A, Mamais D, Lekkas TD. Contribution of primary and secondary treatment on the removal of benzothiazoles, benzotriazoles, endocrine disruptors, pharmaceuticals and perfluorinated compounds in a sewage treatment plant. Sci Total Environ 2013, 463-464:1067-1075.

122. Asimakopoulos AG, Ajibola A, Kannan K, Thomaidis NS. Occurrence and removal efficiencies of benzotriazoles and benzothiazoles in a wastewater treatment plant in Greece. Sci Total Environ 2013, 452-453:163-171.

123. van der Veen I, de Boer J. Phosphorus flame retardants: properties, production, environmental occurrence, toxicity and analysis. Chemosphere 2012, 88:1119-1153.

124. La Guardia MJ, Hale RC, Harvey E. Detailed polybrominated diphenyl ether (PBDE) congener composition of the widely used penta-, octa-, and deca-PBDE technical flame-retardant mixtures. Environ Sci Technol 2006, 40:6247-6254.

125. Houde M, Berryman D, de Lafontaine Y, Verreault J. Novel brominated flame retardants and dechloranes in three fish species from the St. Lawrence River, Canada. Sci Total Environ 2014, 479-480:48-56.

126. EC. Directive 2013/39/EU of the European Parliament and of the Council amending Directives 2000/60/EC and 2008/105/EC as regards priority substances in the field of water policy. 2013. Available at: http:// eur-lex.europa.eu/LexUriServ/LexUriServ.do?uri=OJ: L:2013:226:0001:0017:EN:PDF. (Accessed February 20, 2014).

127. Covaci A, Harrad S, Abdallah MAE, Ali N, Law RJ, Herzke D, de Wit CA. Novel brominated flame retardants: a review of their analysis, environmental fate and behaviour. Environ Int 2011, 37:532-556.

128. Beard A. Flame retardants-online. Available at: http://www.flameretardants-online.com/web/en/106/ 7ae3d32234954e28e661e506e284da7f.htm. (Accessed November 26, 2014).

129. Holmgren T. Emissions of organic compounds from technosphere articles: measurement and modeling of mass transfer from consumer goods and building materials to air and water. 2013. Available at: http:// www.diva-portal.org/smash/get/diva2:606227/FULL TEXT01.pdf. (Accessed March 19, 2014).

130. Andresen JA, Grundmann A, Bester K. Organophosphorus flame retardants and plasticisers in surface waters. Sci Total Environ 2004, 332:155-166.

131. Marklund A, Andersson B, Haglund P. Organophosphorus flame retardants and plasticizers in Swedish sewage treatment plants. Environ Sci Technol 2005, 39:7423-7429.

132. Coelhan M. Levels of chlorinated paraffins in water. CLEAN 2010, 38:452-456.

133. KemI. Perfluorinated substances and their uses in Sweden. 2006. Available at: http://www.kemi.se/ Documents/Publikationer/Trycksaker/Rapporter/ Report7_06.pdf. (Accessed March 20, 2014).

134. Alder AC, van der Voet J. Occurrence and point source characterization of perfluoroalkyl acids in sewage sludge. Chemosphere 2014, 129:62-73. doi:10.1016/j.chemosphere.2014.07.045.

135. Post GB, Cohn PD, Cooper KR. Perfluorooctanoic acid (PFOA), an emerging drinking water contaminant: a critical review of recent literature. Environ Res 2012, 116:93-117.

136. Ahrens L, Felizeter S, Sturm R, Xie Z, Ebinghaus R. Polyfluorinated compounds in waste water treatment plant effluents and surface waters along the River Elbe, Germany. Mar Pollut Bull 2009, 58:1326-1333.

137. Arvaniti OS, Ventouri EI, Stasinakis AS, Thomaidis NS. Occurrence of different classes of perfluorinated compounds in Greek wastewater treatment plants and determination of their solid-water distribution coefficients. J Hazard Mater 2012, 239-240:24-31.

138. Bossi R, Strand J, Sortkjær O, Larsen MM. Perfluoroalkyl compounds in Danish wastewater treatment plants and aquatic environments. Environ Int 2008, 34:443-450.

139. EU. EU Pesticides database. Pesticides (active substances) approved in Europe. Available at: http://ec. europa.eu/sanco_pesticides/public/? event=activesub stance.selection. (Accessed November 27, 2014).

140. EU. Biocides (active substances) approved in Europe. Available at: http://ec.europa.eu/environment/chemi cals/biocides/active-substances/approved-substances_ en.htm. (Accessed November 27, 2014).

141. Burkhardt M, Zuleeg S, Vonbank R, Bester K, Carmeliet J, Boller M, Wangler T. Leaching of biocides from Façades under natural weather conditions. Environ Sci Technol 2012, 46:5497-5503.

142. Coutu S, Del Giudice D, Rossi L, Barry DA. Modeling of facade leaching in urban catchments. Water Resour Res 2012, 48. doi:10.1029/2012WR012359.

143. Wittmer IK, Scheidegger R, Bader H-P, Singer H, Stamm C. Loss rates of urban biocides can exceed those of agricultural pesticides. Sci Total Environ 2011, 409:920-932. 
144. Köck-Schulmeyer M, Villagrasa M, López de Alda M, Céspedes-Sánchez R, Ventura F, Barceló D. Occurrence and behavior of pesticides in wastewater treatment plants and their environmental impact. Sci Total Environ 2013, 458-460:466-476.

145. Katsoyiannis A, Samara C. Persistent organic pollutants (POPs) in the conventional activated sludge treatment process: fate and mass balance. Environ Res 2005, 97:245-257.

146. Bodin N, Tapie N, Le Ménach K, Chassot E, Elie P, Rochard E, Budzinski H. PCB contamination in fish community from the gironde estuary (France): blast from the past. Chemosphere 2014, 98:66-72.

147. Rossi L, de Alencastro L, Kupper T, Tarradellas J. Urban stormwater contamination by polychlorinated biphenyls (PCBs) and its importance for urban water systems in Switzerland. Sci Total Environ 2004, 322:179-189.

148. Poté J, Haller L, Loizeau JL, Garcia Bravo A, Sastre V, Wildi W. Effects of a sewage treatment plant outlet pipe extension on the distribution of contaminants in the sediments of the Bay of Vidy, Lake Geneva, Switzerland. Bioresour Technol 2008, 99:7122-7131.

149. Fu F, Wang Q. Removal of heavy metal ions from wastewaters: a review. J Environ Manag 2011, 92:407-418.

150. Sörme L, Lagerkvist R. Sources of heavy metals in urban wastewater in Stockholm. Sci Total Environ 2002, 298:131-145.

151. Chèvre N, Guignard C, Rossi L, Pfeifer HR, Bader HP, Scheidegger R. Substance flow analysis as a tool for urban water management. Water Sci Technol 2011, 63:1341-1348.

152. Rule KL, Comber SDW, Ross D, Thornton A, Makropoulos CK, Rautiu R. Survey of priority substances entering thirty English wastewater treatment works. Water Environ J 2006, 20:177-184.

153. Buzier R, Tusseau-Vuillemin M-H, dit Meriadec CM, Rousselot O, Mouchel J-M. Trace metal speciation and fluxes within a major French wastewater treatment plant: impact of the successive treatments stages. Chemosphere 2006, 65:2419-2426.

154. Gbondo-Tugbawa SS, McAlear JA, Driscoll CT, Sharpe CW. Total and methyl mercury transformations and mass loadings within a wastewater treatment plant and the impact of the effluent discharge to an alkaline hypereutrophic lake. Water Res 2010, 44:2863-2875.

155. Yoshida H, Christensen TH, Guildal T, Scheutz C. A comprehensive substance flow analysis of a municipal wastewater and sludge treatment plant. Chemosphere 2013. doi:10.1016/j.chemosphere.2013.1009.1045.

156. Rubio-Clemente A, Torres-Palma RA, Peñuela GA. Removal of polycyclic aromatic hydrocarbons in aqueous environment by chemical treatments: a review. $\mathrm{Sci}$ Total Environ 2014, 478:201-225.

157. Liu JJ, Wang XC, Fan B. Characteristics of PAHs adsorption on inorganic particles and activated sludge in domestic wastewater treatment. Bioresour Technol 2011, 102:5305-5311.

158. Byrns G. The fate of xenobiotic organic compounds in wastewater treatment plants. Water Res 2001, 35:2523-2533.

159. Yang J, Wang K, Zhao Q, Huang L, Yuan CS, Chen WH, Yang WB. Underestimated public health risks caused by overestimated VOC removal in wastewater treatment processes. Environ Sci Process Impacts 2014, 16:271-279.

160. Mozo I, Lesage G, Yin J, Bessiere Y, Barna L, Sperandio M. Dynamic modeling of biodegradation and volatilization of hazardous aromatic substances in aerobic bioreactor. Water Res 2012, 46:5327-5342.

161. Abegglen C, Siegrist H. Micropolluants dans les eaux usées urbaines. Etapes de traitement supplémentaire dans les stations d'épuration. Berne, Germany: Office fédéral de l'environnement; 2012, 87.

162. Hollender J, Zimmermann SG, Koepke S, Krauss M, McArdell CS, Ort C, Singer H, von Gunten U, Siegrist H. Elimination of organic micropollutants in a municipal wastewater treatment plant upgraded with a full-scale post-ozonation followed by sand filtration. Environ Sci Technol 2009, 43:7862-7869.

163. Eggen RIL, Hollender J, Joss A, Schärer M, Stamm C. Reducing the discharge of micropollutants in the aquatic environment: the benefits of upgrading wastewater treatment plants. Environ Sci Technol 2014, 48:7683-7689.

164. Gregorio V, Chèvre N. Assessing the risks posed by mixtures of chemicals in freshwater environments: case study of Lake Geneva, Switzerland. WIREs Water 2014, 1:229-247.

\section{FURTHER READING/RESOURCES}

Aquatic impact indicator (ecotoxicity) database AiiDA. Available at: http://aiida.tools4env.com.

Ecotox Centre of the Eawag/EPFL, Proposals for Acute and Chronic Quality Criteria. Available at: http://www.oekotoxzentrum.ch.

Swiss information platform related to micropollutant removal from wastewater. Available at: http://www.micropoll.ch. 